\title{
Prognosis of Wind-tempted Mean Pressure Coefficients of Cross-shaped Tall Buildings Using Artificial Neural Network
}

\author{
Rajdip Paul ${ }^{*}$, Sujit Kumar Dalui ${ }^{1}$ \\ ${ }^{1}$ Civil Engineering Department, Indian Institute of Engineering Science and Technology, Shibpur, Botanic Garden, Shalimar, West \\ Bengal, 711103 Howrah, India \\ * Corresponding author, e-mail: rajdippaul.rs2014@civil.iiests.ac.in
}

Received: 23 April 2020, Accepted: 14 July 2020, Published online: 25 August 2020

\begin{abstract}
The present paper focuses on the study of wind-induced responses of cross-plan shaped tall buildings. Initially, three parametric building models are studied for the purpose with a constant plan area $22500 \mathrm{~mm}^{2}$. The length and velocity scales are taken as 1:300 and 1:5, respectively. Wind angle of attack (WAA) is considered from $0^{\circ}$ to $330^{\circ}$ with an increment of $30^{\circ}$. At first, the external surface pressure coefficients $\left(C_{p}\right)$ at different faces of the models are carried out for different wind occurrence angles employing Computational Fluid Dynamics method of simulated wind flow. Again, Fast Fourier Transform (FFT) fitted expressions as the sine and cosine function of WAA are proposed for attaining mean wind pressure coefficient on the building faces. The accuracy of the Fourier series expansions is justified by presenting histograms of sum square error (SSE), $R^{2}$ value and root mean square error (RMSE). The results are also compared by training Artificial Neural Networks (ANN). Training is continued till Regression $(R)$ values are more than 0.99 and Mean Squared Error (MSE) tends to 0, ensuring a close relationship among the outputs and targets. The face-wise value of $\left(C_{p}\right)$ obtained using all three methods, are plotted. The error histograms of the ANN models show that the fitting data errors are spread within a reasonably good range. It is observed that the deviation in the result is not more than $5 \%$ in any case. Finally, the ANN predictions are presented for nine parametric models to cover a wide range of possible cross-shaped buildings.
\end{abstract}

Keywords

cross-plan, tall building, Artificial Neural Network (ANN), Fast Fourier Transform (FFT), pressure coefficient, regression

\section{Introduction}

With the advent of modern technology and scarcity of available land in the globe, modern buildings are very tall and also non-conventional and irregular in both plan shape and elevation. Thus, tall buildings being susceptible to lateral forces (Part-especially for the response of across direction), may vibrate in all the three directions $(\mathrm{x}, \mathrm{y}, \mathrm{z})$. As the building height increases, wind becomes the predominant lateral force as the wind intensity intensifies exponentially with the altitude of the building. Not only that, but wind-induced responses depend significantly upon the shape of the building also. Different International Standards are providing guidelines for estimating wind-induced responses for regular (both in plan and elevation) shaped buildings. But non-conventional, irregularly shaped structures demand guidance from specialized literature or wind tunnel study or CFD approach. Over the years, wind tunnel model experiments were conducted by the researchers to study localized wind forces [1], experimental results of $U$ and $L$ shaped building in the plan [2], occupant comfort under dynamic wind [3], the effect of size of recessed and chamfered corners of tall buildings [4], aerodynamic forces and wind pressure on various unconventional configurations [5], pressure coefficients on the walls of the buildings $\left(C_{p e}\right)$ and propose surrogate models [6], the deviation of pressure dispersal of tall square plan shaped building for various wind azimuths [7] so on and so forth. In some cases, a combination of wind tunnel study and numerical simulation was also carried out to demonstrate wind-induced responses of ' + ' shaped in plan tall building model for $0^{\circ}$ as well as $45^{\circ}$ [8], mean pressure coefficient of ' $E^{\prime}$ plan shaped tall building [9]. Again numerical simulation techniques were adopted to study wind tempted interference characteristics [10], turbulent scalar flux for near-field scattering around buildings [11], the variation of external pressure coefficients and force coefficients on ' $Z$ ' plan 
shaped tall building [12], wind response for regular and angular cross plan shaped building model [13], the effect of horizontal modifications like corner cut on tall building [14], the variation of pressure due to the presence of the courtyard and opening of a rectangular plan shaped building numerically and analytically [15] and so on. Wind tunnel tests being strenuous, expensive, time-consuming, and a very complex problem may not always be adopted. Later Computational fluid dynamics has been found as a suitable alternative to predict fairly accurate wind-induced responses on structures. But because of the assumptions associated with the problem of CFD and many flow situations during wind-structure interaction, the data acquired using CFD should be suitably compared with experimental results or other modes of prediction. The comparison can be aptly carried out using Artificial Neural Network (ANN), which is a proficient tool for analyzing complex engineering problems and also proven to deliver feasible solutions. ANN can be effectively used to develop functional relationships between input and associated output parameters derived from any source [16]. Thus, ANN can be conveniently used to create a generalized relationship from limited and occasionally erratic input data. Many researchers had applied and reported ANN to be extremely efficient to solve complex engineering problems. In the past few decades, ANN has become exceedingly popular and found its application not only in the wind engineering studies but many civil and structural engineering research problems.

ANN had a widespread application in the field of civil engineering since long. It was applied in the development of the backpropagation neural net and the improved counter-propagation neural net for the analysis and design of large scale space structures [17] and also for the presentation of a neurocomputing strategy combining neural networks and numerical structural optimization [18]. Again ANN was used to train efficient backpropagation neural networks for design of double-layer grids [19], to train neural networks that predict $M-\phi$ diagrams for the type of connection considered and for saddle-like connection with sufficient accuracy [20, 21]. Further, to develop fuzzy neural networks (FNN) approach to predict mean pressure distributions on the roof model and to identify the patterns of pressure distribution, ANN was applied [22]. ANN was combined with a genetic algorithm to form a complete design and optimization approach for transmission tower [23] and to develop a robust simulation-based optimization scheme using an ANN-surrogate model [24].
ANN found its application specifically in the field of wind engineering too. ANN was utilized to predict wind spectra and to calculate wind loadings for rectangular cross-section buildings [25]. Further, to present an innovative method for investigating the seismic vulnerability of the existing concrete structures with moment resisting frames (MRF) [26] and to generalize the across wind response of tall and slender buildings from the inadequate existing data so that across wind response can be attained for a building with specified (h:b:d) ratio [27], ANN was adopted. Neural nets were used to estimate mean external surface pressure coefficients of tall buildings [28] and to propose a simplified approach for estimating the dynamic along-wind response of tall buildings based on Indian Wind Code [29, 30]. Again for stabilizing proper orthogonal decomposition-based reduced-order models for quasi-static geophysical turbulent flows [31], to propose an efficient and cost-effective computational tool that can be applied to estimate the wind response of a building [16], ANN was used. ANN also helped the researchers to present a numerical methodology combining regression analysis with flow modal decomposition for constructing reduced-order models of fluid flows [32] and also to develop equations of wind-induced pressure coefficient using experimental data, for the group method of data handling neural network that can efficiently predict average surface pressure coefficients on the projected surface of different C-shaped building models [33].

In the present study, wind-induced responses are comprehensively studied for Cross plan-shaped tall buildings. More precisely, mean wind pressures on different faces of three tall buildings are considered for wind occurrence angle varying from $0^{\circ}$ to $330^{\circ}$ at an increment of $30^{\circ}$. At first, a numerical study is performed using RANS $\mathrm{k}-\varepsilon$ turbulence model by CFD. The CFD is suitably calibrated with available experimental results. Mean pressure coefficient $\left(C_{p}\right)$ on the different building faces of the buildings are proposed numerically. Again, the wind flow pattern around the building for one orthogonal and one skew wind angle of attack is shown to through light on the wake regions where the vortex shedding is taking place under the turbulent wind. Afterwards, Fast Fourier Transform (FFT) fitted expressions as the sine and cosine function of wind incidence angle are proposed for attaining mean wind pressure coefficients. Finally, the results are compared by training Artificial Neural Networks (ANN). The ANN predictions are compared among different parametric models. 


\section{The parametric models of the study}

As discussed, rectangular with horizontal limbs to form cross-plan shaped tall building is taken as the parametric building model. Initially, three models are generated and studied to understand the shape effect on pressure distribution among different faces of the building. The external pressure distribution on the several surfaces of the building $\left(C_{p e}\right)$ is studied with different wind direction. The building model defining building surfaces, dimensions and wind incidence angles, is shown in Fig. 1. Dimension $b$ is varied among three building models to change the $d / b$ and $h / b$ ratios, where $h$ is the height of the building. The plan area of the building is 22500 $\mathrm{mm}^{2}$. The detailed specifications of the parametric building models are presented in Table 1. After comparison of results obtained using CFD, FFT and ANN for three parametric models, ANN predictions of $C_{p e}$ for additional six models (including a '+' shaped model for which calibration of CFD is done in Section 5) are also presented to carry out a comprehensive study. Details of the additional

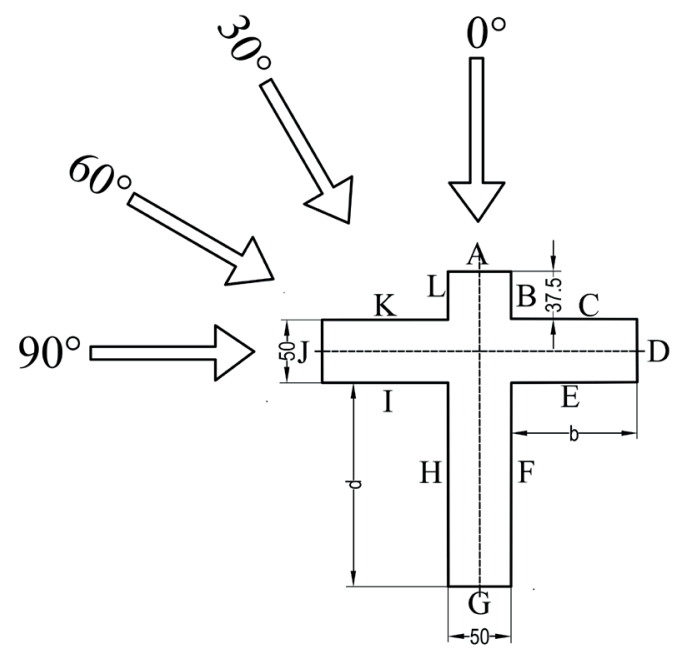

Fig. 1 Plan of building models describing surfaces, dimensions, and wind incidence (all dimensions are in $\mathrm{mm}$ )

models are given in the figure titled "Definition of the building surfaces and dimensions of six additional models for the comprehensive study (All units are in "mm")" on the page 10 .

Table 1 Geometry of different cross-plan shaped buildings

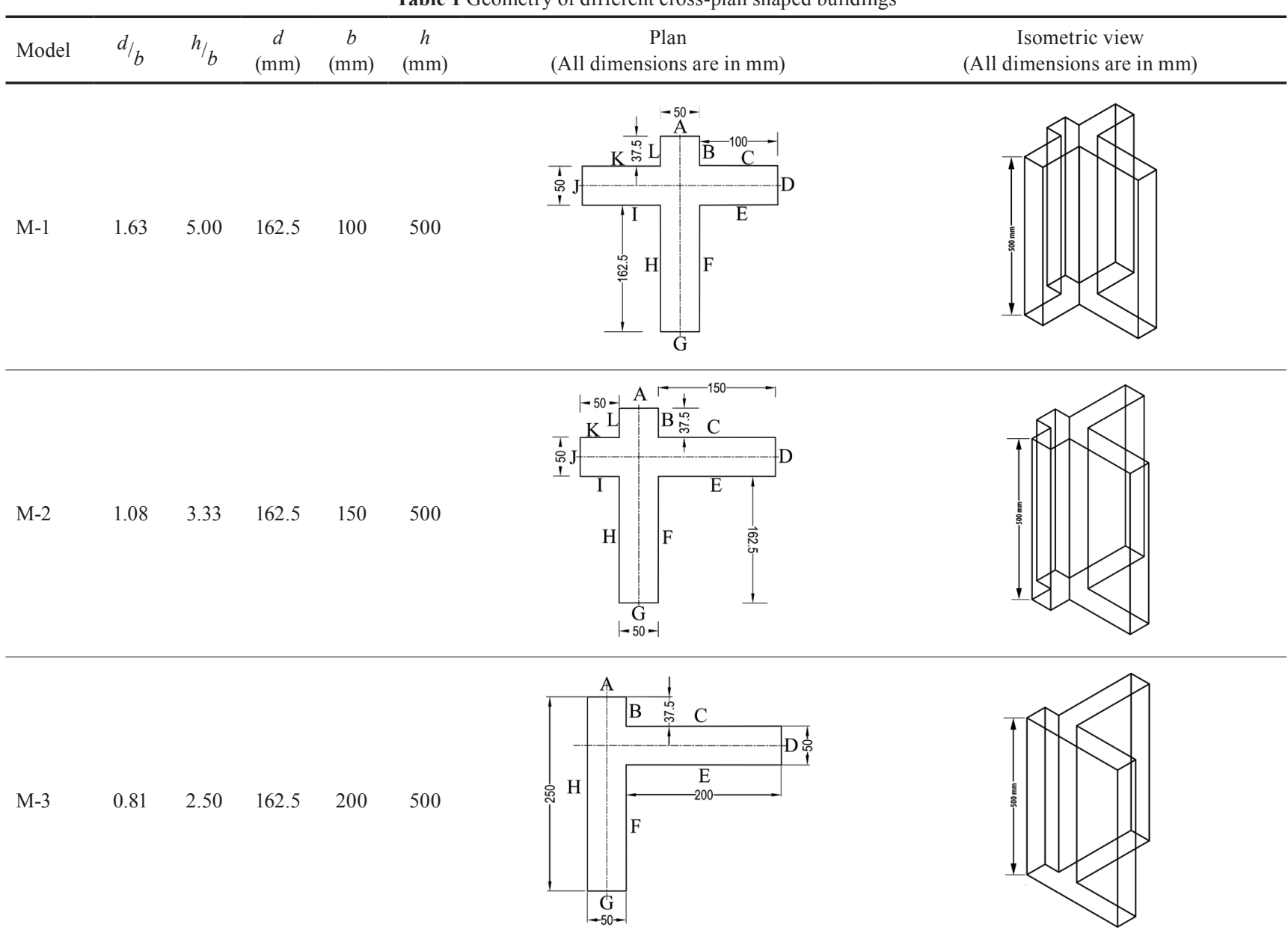




\section{The domain used in Computational Fluid Dynamics (CFD)}

While performing a numerical simulation, the volume in which the flow has to be computed need to be well defined and usually designated as computational domain. A reasonably large domain invariably increases the number of cells after meshing the entire domain. But a coarser meshing is sufficient in regions far away from the building surfaces or wake region. Hence the domain size for CFD, especially for a tall building shall be chosen rationally so that the analysis time does not increase needlessly. Revuz et al. [34] prescribed the suitable domain size for tall buildings considering the effects of varying the domain size around a tall building. They took into account the generation of vortices and fluctuations in velocity in the region of disturbed flow (turbulent) downstream of the building caused by the wind flow are derived with sufficient accuracy. They recommended the domain size having an inlet, top and two side clearance of $15 \mathrm{H}$ and outlet clearance of $5 H$ from the building edges, where $H$ is the building height. The domain used for the study is shown in Fig. 2(a) and Fig. 2(b).

\section{Meshing and boundary conditions}

An amalgamation of tetrahedral meshing and hexahedral meshing is used to mesh the entire domain as well as the building walls. Very fine hexahedral meshes are generated close to the building surfaces by the pre-processing software which helped in simulating even flow. Uniform coarser tetrahedral meshing in rest of the domain is taken

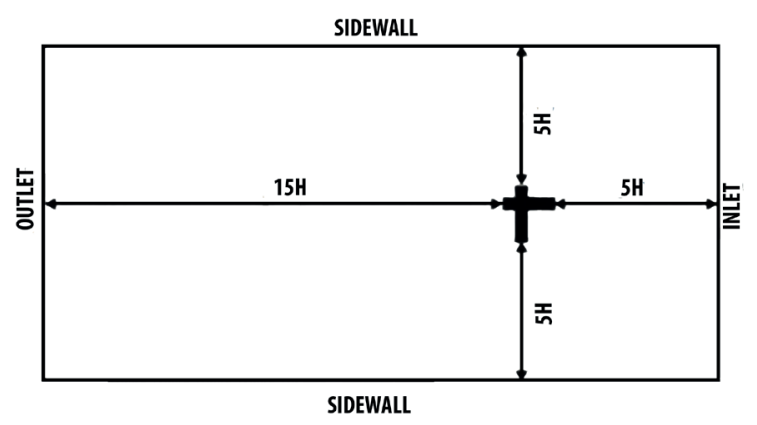

(a)

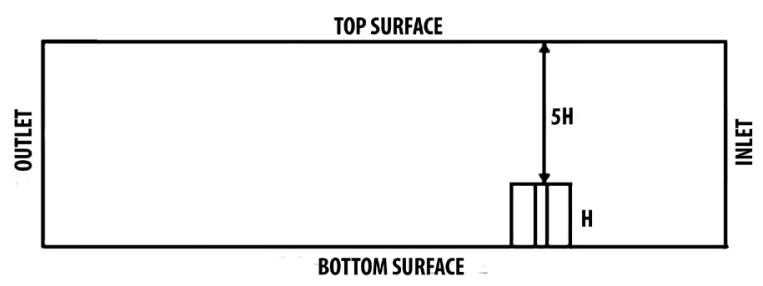

(b)

Fig. 2 (a) Plan of the domain, (b) Elevation of the domain

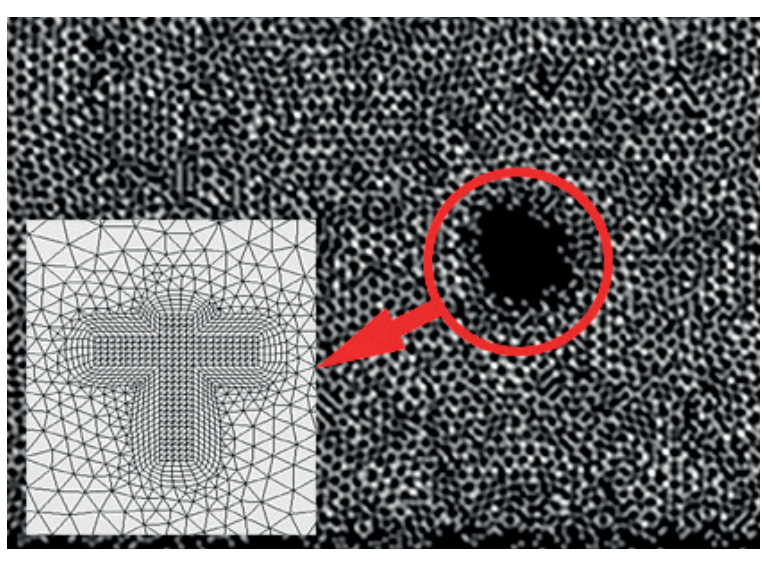

(a)

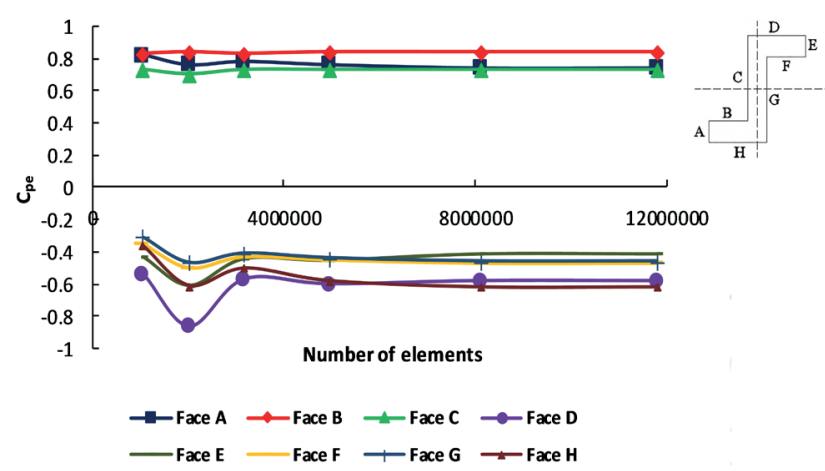

(b)

Fig. 3 (a) Meshing used around the building and domain, (b) Results of grid independence test

up to lessen the time of analysis significantly negating any considerable harm in precision. The meshing thus adopted is shown in Fig. 3(a) with an enlarged view near the building model in the inset. The first grid points adjoining the wall were located at $y+>30$ to implement empirical wall functions.

Grid independence is an essential criterion in any CFD method to derive the conclusion that further reduction in grid size does not lead to any more precision in the results. The grid independence test is carried out by trial and error method decreasing the grid size in each trial resulting subsequent increase in the number of elements in the domain. Initially, a $\mathrm{Z}$ shaped building model is designed in the pre-processing software ( $A N S Y S C F X-C F D$ ). The mesh is generated several times, and the pressure coefficients for different faces of the buildings are extracted corresponding to $0^{\circ}$ wind incidence angle. The results obtained in each case are checked for the grid accuracy corresponding to the results of Paul and Dalui [12]. Based on the grid dependency test, the optimal number of elements is obtained at 8.1 million. The outcomes of grid independency study are shown in Fig. 3(b). 
A high degree of similitude between the boundary conditions of both the numerical and the experimental methods should be achieved mainly for inlet or inflow boundary. The boundary layer flow was generated using power-law with $\alpha=0.133$ to accomplish the desired terrain category as per IS: 875 (Part 3) [29]. The velocity profile near the windward side is compared for the numerical method and wind tunnel measurement. The velocity profile is nearly alike, as observed in Fig. 4 [35]. The turbulence intensity

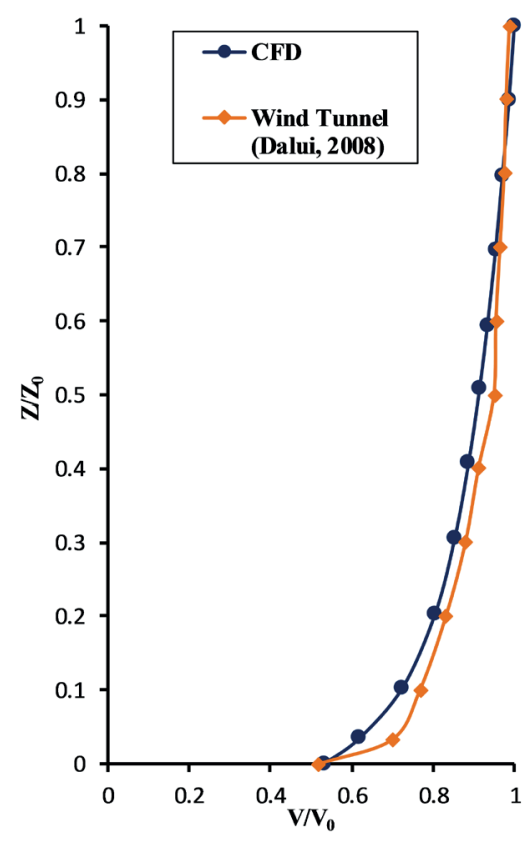

Fig. 4 The velocity profile

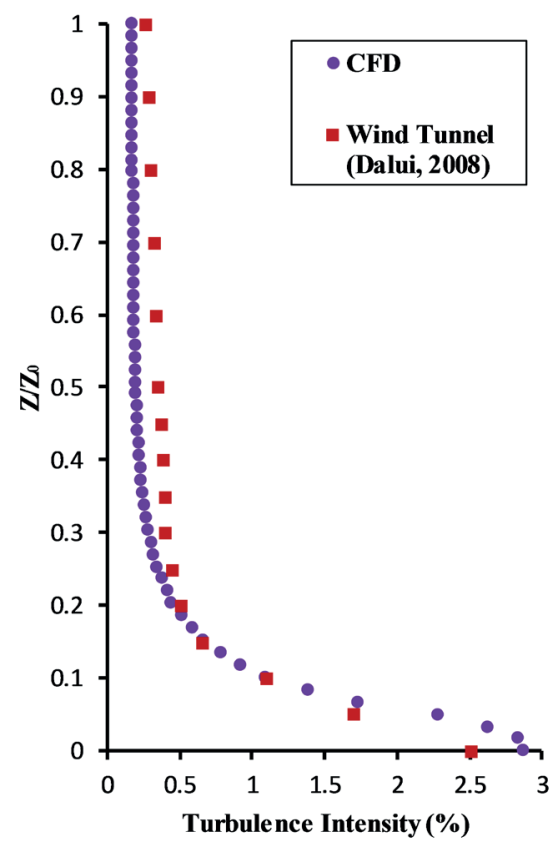

Fig. 5 Turbulence intensity along the building height was also compared for numerical method and wind tunnel measurement and is presented in Fig. 5 [35]. The turbulence intensity was also matching with good agreement for both methods.

\section{Calibration of CFD with experimental results}

The numerical simulation technique adopted for this particular study is calibrated using the experimental data available for a ' + ' shaped tall building. Chakraborty et al. [8] presented the external pressure coefficients $\left(C_{p e}\right)$ on different faces of a '+' shaped tall building obtained from wind tunnel model experiment and $k-\varepsilon$ numerical simulation. The height-ratio and the plan-ratio of the building are similar to the parametric models adopted for the present study. The '+' shaped model defining building surfaces, dimensions and wind incidence angles are shown in Fig. 6 (The wind angles and the building surfaces are designated comparing the present study). The experiment was carried out in the boundary layer wind tunnel (BLWT) at Wind Engineering Centre, Department of Civil Engineering, Indian Institute of Technology Roorkee, India [8]. The BLWT was an open circuit suction type tunnel in which the suction flow is generated with a blower fan of $125 \mathrm{HP}$ capacity [8]. The test section was $2 \mathrm{~m}$ (height) $\times 2 \mathrm{~m}$ (width) $\times 38 \mathrm{~m}$ (length) [8] An elliptical effuse profile having a contraction ratio of 9.5:1 along with a $6 \mathrm{~m} \times 6 \mathrm{~m}$ squared-holed Honeycomb was located at the entrance of the tunnel [8].

The wind flow pattern around the building model corresponding to $0^{\circ}, 45^{\circ}$ and $60^{\circ}$ wind incidence angles is shown in Figs. 7(a) to (c), respectively, to represent the effect of wind angle on the formation of wake region and vortices. As the building model is symmetric concerning both axes, the vortices formed downstream the building are also symmetric under wind angle $0^{\circ}$ and $45^{\circ}$. This implies, under $0^{\circ}$ and $45^{\circ}$ wind occurrences, symmetrical

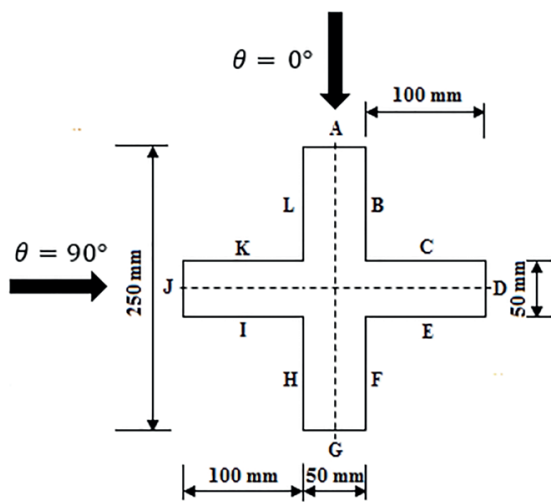

(a) Plan

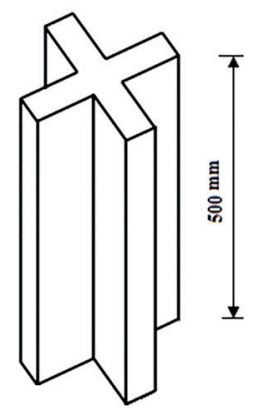

(b) Isometric View
Fig. 6 Plan and 3-D view of the '+' shaped building model 


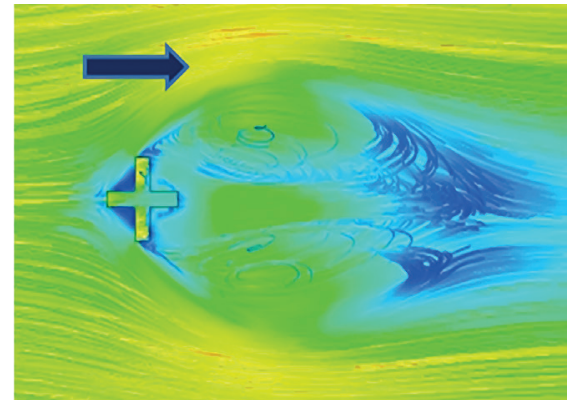

a) $0^{\circ}$,

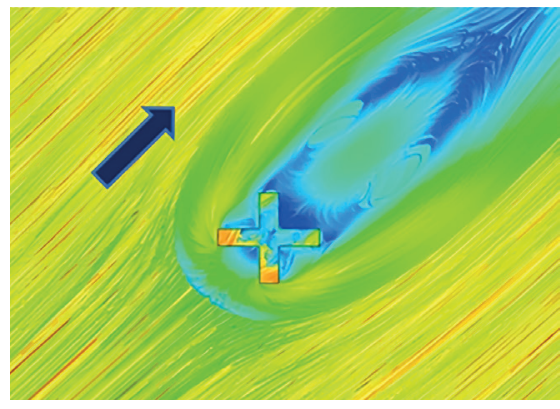

b) $45^{\circ}$,

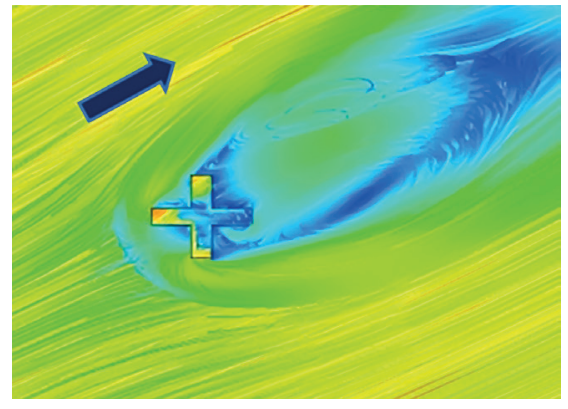

c) $60^{\circ}$

Fig. 7 Wind streamlines around the ' + ' shaped building model for different wind angles

surfaces of the building will experience the same distribution of pressure. Whereas for $60^{\circ}$ wind angle of attack, the vortices are somewhat chaotic in nature.

The values of the pressure coefficients achieved for the ' + ' model form the present study are compared with the results of the wind tunnel study and k- $\varepsilon$ numerical simulation presented by Chakraborty et al. [8]. The comparison of results for different building surfaces is shown in Figs. 8(a) to (1). It is observed that the results achieved from the numerical method considering the $k-\varepsilon$ viscosity model (both past and present) show a reasonably good agreement with experimental results. Though, some discrepancies are observed in zones of high vorticity like Face B and Face $\mathrm{C}$ under $45^{\circ}$ wind angle of attack, Face $\mathrm{E}$ and Face $\mathrm{F}$ under $135^{\circ}$ wind angle. However, the variance in the mean pressure coefficient, obtained from the numerical and the experimental method is within the permissible limit.

\section{Fast Fourier Transformation (FFT) methodology}

The Fourier expansion has been utilized as the sum of sine and cosine function to propose analytical expression for determining surface pressure and force coefficients [9]. The Fourier expansion, in general, is given by,

$f(x)=a_{0}+\sum_{i=1}^{n}\left(a_{i} \cos i \omega x+b_{i} \sin i \omega x\right)$,

where, $a_{0}$ is the constant, which is also intercept of the model, $\omega$ is the frequency of the signal or, the predictive function. In this equation, $i$ should be truncated at some finite number $n$ to develop a proper harmonic polynomial. $a_{i}$ and $b_{i}$ are the coefficients of the harmonic terms [9]. To propose polynomial for the different faces of the building with the Fourier series as provided in (1), $n=2$ has been chosen for the present study. So, the Fourier expansion becomes,

$$
\begin{aligned}
f(x) & =a_{0}+a_{1} \cos (\omega x)+b_{1} \sin (\omega x) \\
& +a_{2} \cos (2 \omega x)+b_{2} \sin (2 \omega x),
\end{aligned}
$$

where $x$ is the wind incidence angle in degree and $f(\mathrm{x})$ denotes the mean pressure coefficients and force coefficients. Three different error measurements have been performed in this study to check the accuracy of the fitted models, namely sum squared error (SSE), also known as the residual sum of square (RSS), The value of $R^{2}$ which is a widely used statistical measure to check the feasibility of the model and root mean square error (RMSE). The expressions for all the three error measurement procedure are given below.

$$
\begin{aligned}
& S S E=\sum_{i=1}^{n}\left\{y_{i}-f\left(x_{i}\right)\right\}^{2} \\
& R^{2}=1-\frac{\sum_{i=1}^{n}\left\{y_{i}-f\left(x_{i}\right)\right\}^{2}}{\sum_{i=1}^{n}\left(y_{i}-\bar{y}\right)^{2}} \\
& R M S E=\sqrt{\frac{1}{n} \sum_{i=1}^{n}\left\{y_{i}-f\left(x_{i}\right)\right\}^{2}}
\end{aligned}
$$

\section{The architecture and algorithm used in Artificial Neural Network}

The selection of the network architecture, training algorithm, number of neurons and patterns to be used for the training should be rational and comply not only to the kind of study being carried out but also the volume of the study. In fact, one of the significant challenges of doing research using neural networks is to select the appropriate size and topology of the networks. Because often neural networks are trained to negligible errors, the response is not suitable for patterns other than those being used in training. A general tendency among researchers is to use a large number of neurons to limit the error but Hunter et al. [36] proposed to use minimum neurons along with a considerable amount of training patterns, which can lead to a good response of neural nets for almost all patterns. 


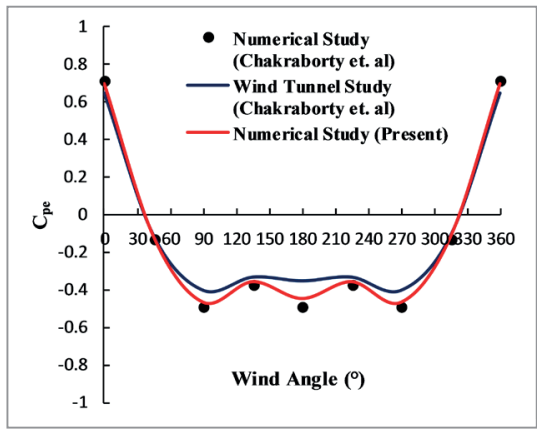

(a) Face $\mathrm{A}$

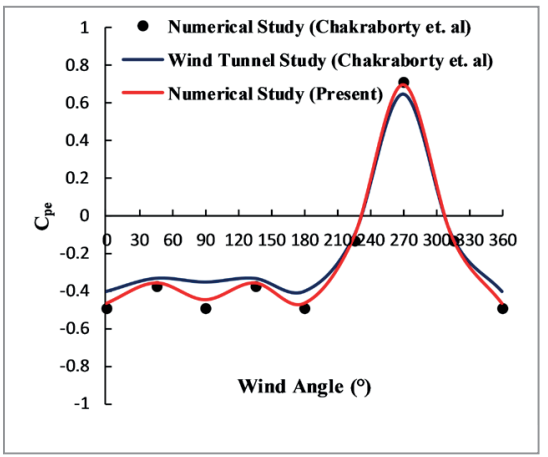

(d) Face D

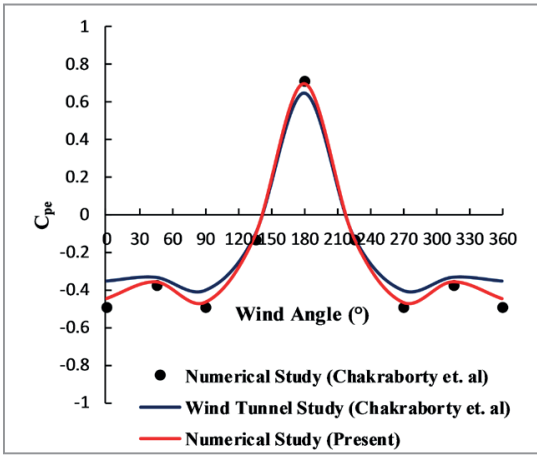

(g) Face G

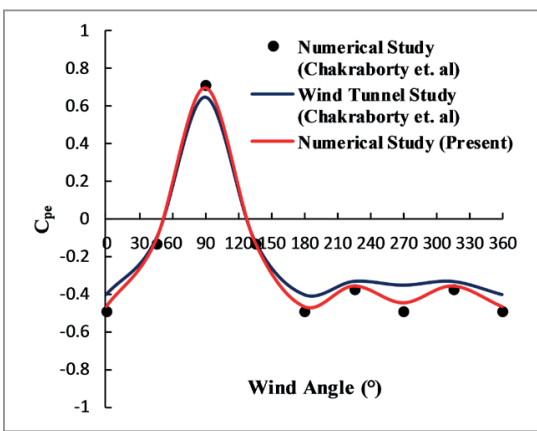

(j) Face J

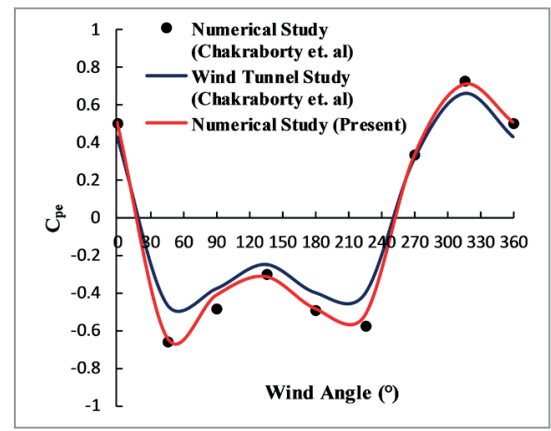

(b) Face B

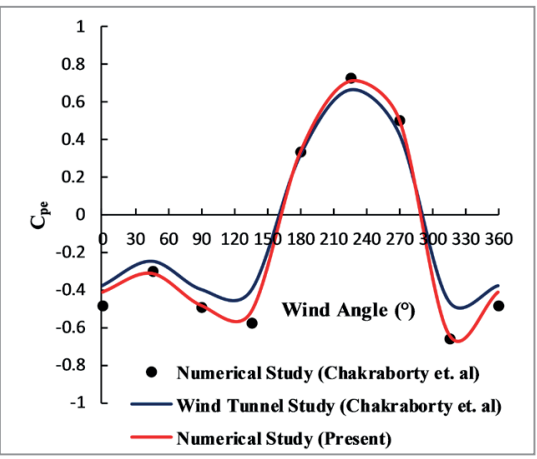

(e) Face E

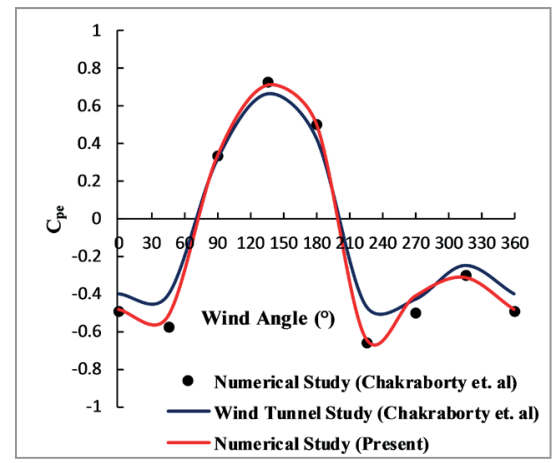

(h) Face $\mathrm{H}$

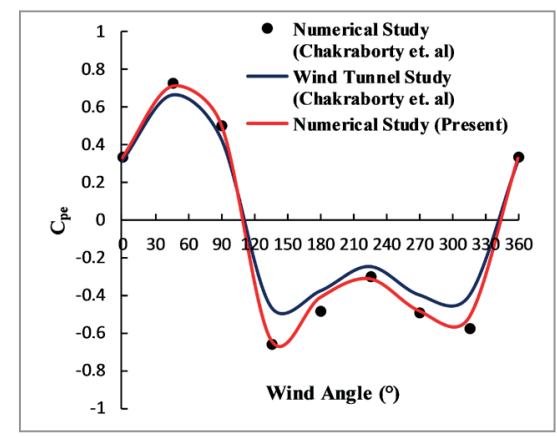

(k) Face K

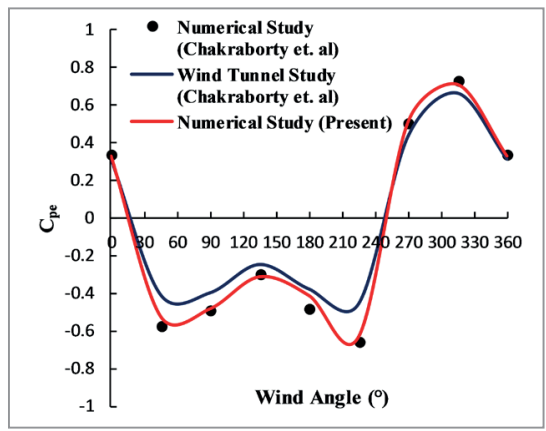

(c) Face $\mathrm{C}$

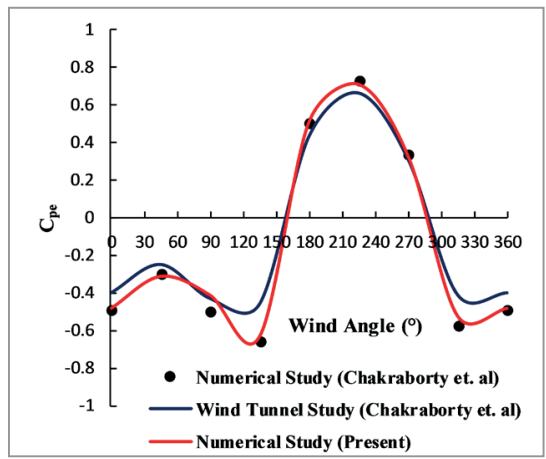

(f) Face $\mathrm{F}$

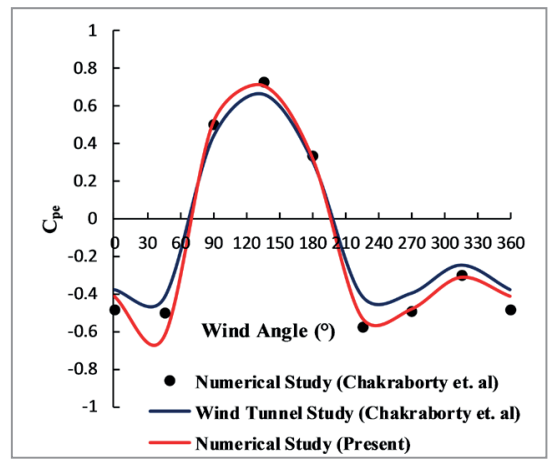

(i) Face I

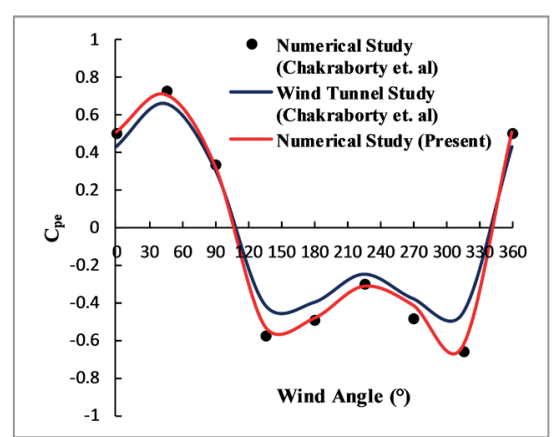

(1) Face L

Fig. 8 The comparison of pressure coefficients obtained using experimental and numerical methods 
In the present study, the Levenberg-Marquardt (LM) algorithm and Multilayer Perceptron (MLP) architecture (Feed-forward backpropagation) are used [37-39]. Levenberg [37] and Hagan and Marquardt [39] proposed that among several second-order methods for neural network training, the most efficient is the Levenberg Marquardt (LM) algorithm. Even then there are problems with this algorithm like using this only MLP network architectures can be trained [39] and only comparatively small problems with only a few patterns can be solved using this algorithm [36]. The study has been carried out using the MATLAB Neural Network Toolbox, which has both first and second-order training algorithms, but it can only train MLP networks. As the associated data with the current study is not huge, MATLAB Neural Network Toolbox is chosen with three neurons in Feedforward backpropagation (FFBP) network. The general architecture of the network is shown in Fig. 9.

Levenberg-Marquardt algorithm is primarily applied in the least-squares curve-fitting problems. For a given set of $m$ empirical pairs $\left(x_{i}, y_{i}\right)$ of independent and dependent variables, the algorithm derives the parameters $\beta$ of the model curve $f(x, \beta)$ so that $S(\beta)$, the sum squared error (SSE) is minimized.

$\hat{\beta} \in \arg \min _{\beta} S(\beta)=\arg \min _{\beta} \sum_{i=1}^{m}\left\{y_{i}-f\left(x_{i}, \beta\right)\right\}^{2}$

is supposed to be non-empty.

Similar to other numeric minimization techniques, the L-M algorithm is also an iterative process [37, 39]. The minimization process triggers with a primary prediction of the parameter vector $\beta$. If there exists only one minimum, a regular guess like $\beta^{T}=(1,1, \ldots, 1)$ is sufficient. But in cases of multiple minima, the algorithm can yield the global minimum based on the closeness of the preliminary guess with the actual solution.

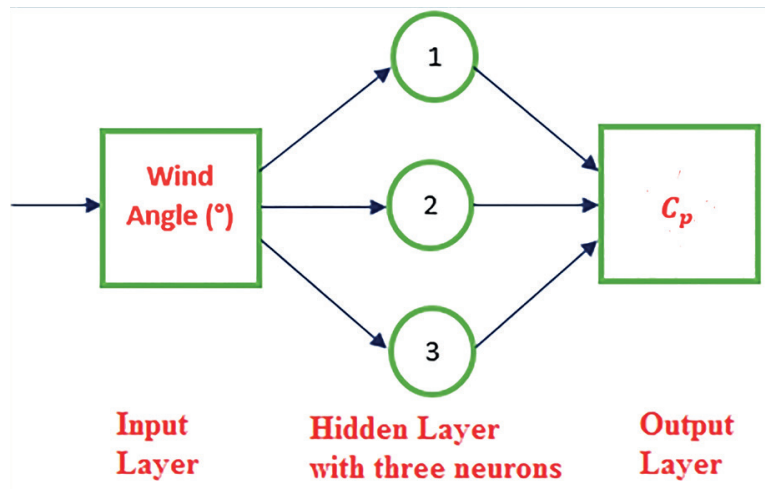

Fig. 9 The three neurons FFBP network
In every step of the iteration, the predicted vector $\beta$ is substituted by a new approximation $\beta+\delta$ To determine $\delta$, the function $f\left(x_{i}, \beta+\delta\right)$, is estimated by:

$f\left(x_{i}, \beta+\delta\right) \approx f\left(x_{i}, \beta\right)+J_{i} \delta$,

where,

$J_{i}=\frac{\partial f\left(x_{i}, \beta\right)}{\partial \beta}$ is the gradient of $f$ concerning $\beta$.

The SSE, $S(\beta)$ is minimum at a zero gradient concerning $\beta$. The above first-order approximation of $f\left(x_{i}, \beta+\delta\right)$,

gives $S(\beta+\delta) \approx \sum_{i=1}^{m}\left\{y_{i}-f\left(x_{i}, \beta\right)-\mathrm{J}_{i} \delta\right\}^{2}$,

The above in vector notation becomes,

$$
\begin{aligned}
S(\beta+\delta) \approx & \|y-\mathrm{f}(\beta)-\mathrm{J} \delta\|^{2} \\
& =[y-f(\beta)-J \delta]^{T}[y-f(\beta)-J \delta] \\
& =[y-f(\beta)]^{T}[y-f(\beta)]-[y-f(\beta)]^{T} J \delta \\
& -(J \delta)^{T}[y-f(\beta)]+\delta^{T} J^{T} \delta \\
& =[y-f(\beta)]^{T}[y-f(\beta)]-2[y-f(\beta)]^{T} J \delta+\delta^{T} J^{T} \delta .
\end{aligned}
$$

If the derivative of $S(\beta+\delta)$ concerning $\delta$, is fixed equal to zero,

$\left(J^{T} J\right) \delta=J^{T}[y-f(\beta)]$,

where $J$ is the Jacobian matrix, whose $i$-th row equals $J_{i}$, and where $f(\beta)$ and $y$ are vectors with $i$-th component $f\left(x_{i}, \beta\right)$ and $y_{i}$ respectively. The Jacobian matrix, as defined above, in general, is a rectangular matrix of size $m \times n$, where $n$ is the number of parameters in the vector $\beta$. The matrix multiplication $\left(J^{T} J\right)$ produces the required $n \times n$ square matrix and the matrix-vector product on the right-hand side yields a vector of size $n$. The result is a set $n$ linear equations, which can be solved for $\delta$.

Levenberg introduced damping in Eq. (8) and modified the same with,

$$
\left(J^{T} J+\lambda I\right) \delta=J^{T}[y-f(\beta)],
$$

where the identity matrix is denoted with $I$, and $\lambda$ is the non-negative damping factor adjusted at every iteration. If $S$ reduces rapidly, a smaller value of $\lambda$ may be used, to bring the algorithm to the vicinity of the Gauss-Newton algorithm. But if it doesn't, $\lambda$ can be assigned a slightly higher value, giving a step closer to the gradient-descent direction. Notably, the gradient of $S$ with respect to $\beta$ equals $2\left(J^{T}[y-f(\beta)]\right)^{T}$. Hence, for large values of $\lambda$, the 
step will be approximated in the opposite direction of the gradient. If either the length of the $\delta$ or the reduction of sum of squares from the newest parameter vector $\beta+\delta$ fall below predefined bounds, iteration stops, and the last parameter vector $\beta$ is taken as the solution.

Fig. 10 is the flow chart depicting the development of the proposed Feed-forward backpropagation ANN model.

\section{Results and discussions}

The configuration of wind flow around the building models for $120^{\circ}$, and $180^{\circ}$ wind incidence angles are shown in Figs. 11(a) and 11(b) respectively to represent the shape effects on the formation of wake region under both orthogonal and skew wind angle of attack. The chaotic nature of the turbulent wind flow and vortex generation in the wake region is apparent from the streamlines. As M-1 is symmetric, the streamlines are also symmetric concerning the vertical axis under $180^{\circ}$ wind incidence angle. Whereas, M-2 and M-3 being asymmetric in plan shape are subjected to much more chaotic streamlines even under $180^{\circ}$ wind angle. The governing frequency of the vortex shedding is the cause of the shaking of the building with increased amplitude.

As discussed earlier, the external surface pressure coefficients, $C_{p e}$ (Average Face value) are obtained from numerical simulation for different faces of the building.
The numerical simulation data are utilized to form FFT polynomials to predict the mean wind pressure for each face. The constant parameters of the polynomials for mean pressure coefficient $C_{p e}$ for three building models are presented in Table 2. The precision of the fitted FFT polynomials are justified with sum squared error (SSE), $R^{2}$ value and root mean square error (RMSE). All the error measurements are hence plotted in Figs. 12(a)-(c). Fig. 12(a) represents that SSE for all the fitted models is less than 0.1 indicating the acceptability of the polynomials. The maximum value of SSE, including all building models, is less than 0.09. Again it is evident from Fig. 12(b) that the $R^{2}$ values for all polynomials lie between 0.95 and 1 , which is well within acceptable limit for fitting any data. In fact, in all cases $R^{2}$ value is more than 0.97., which is extremely good. Also, the RMSE values, as shown in Figs. 12(c), varies from 0.04 to 0.12 , is within the permissible limit for all cases. Hence, all the predicted Fourier series expansion could be applied for predicting mean pressure coefficient on different faces of the building models for any particular wind incidence angle varying from $0^{\circ}$ to $330^{\circ}$.

After FFT polynomials are developed, ANN is further utilized to carry out a more comprehensive and reliable study. As discussed in the preceding section, the mean squared error (MSE) is diminished in each case to keep

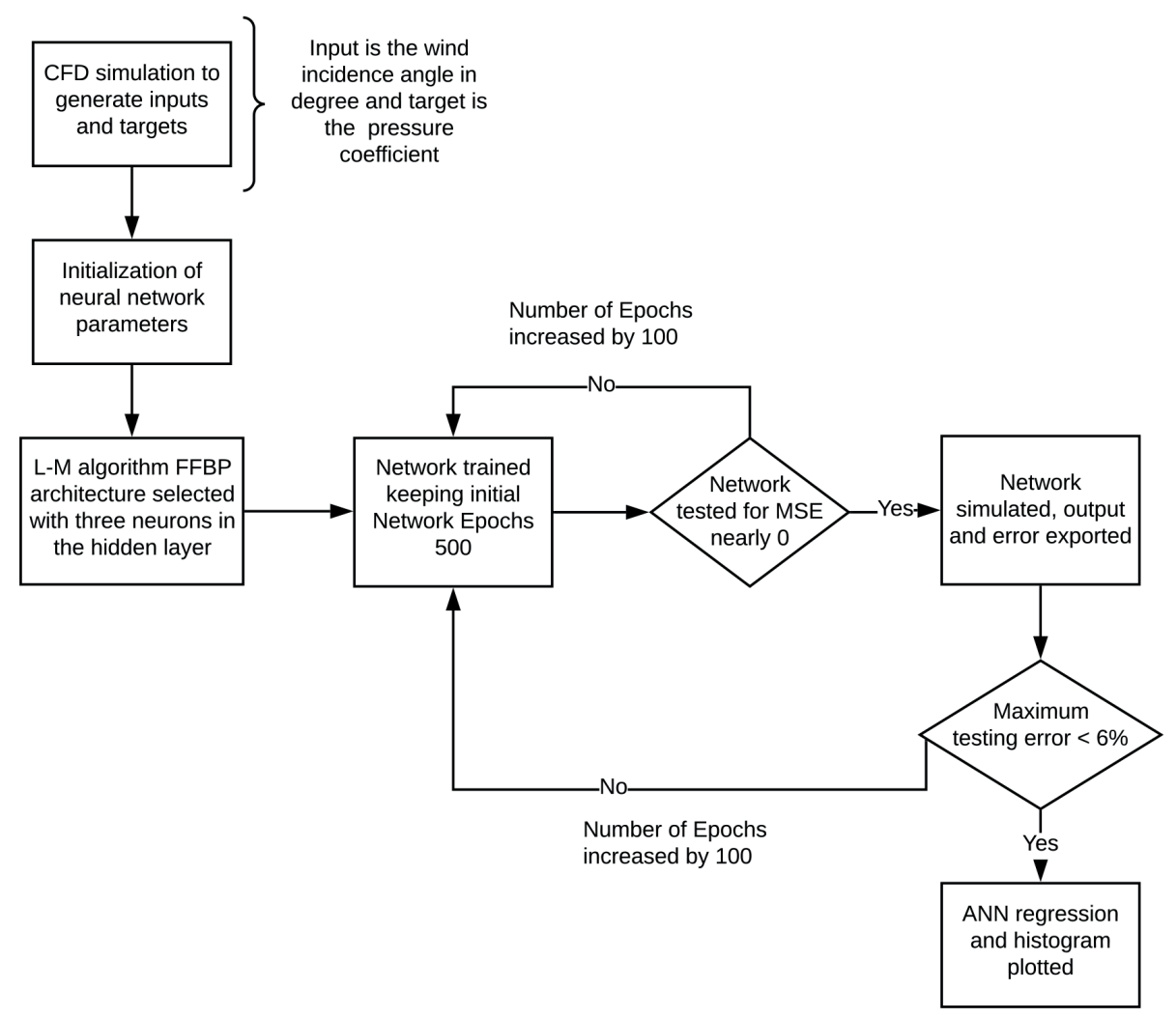

Fig. 10 The flow chart of the development of the FFBP network 
Table 2 Constants of Fourier polynomials for pressure coefficients

\begin{tabular}{|c|c|c|c|c|c|c|c|}
\hline \multirow{2}{*}{ Face } & \multirow{2}{*}{ Model } & \multirow{2}{*}{$\omega$} & \multicolumn{5}{|c|}{ Constants } \\
\hline & & & $a_{0}$ & $a_{1}$ & $b_{1}$ & $a_{2}$ & $b_{2}$ \\
\hline \multirow{3}{*}{ A } & M-1 & 0.01552 & -0.1311 & 0.7642 & -0.2811 & 0.3563 & -0.3065 \\
\hline & M-2 & 0.01468 & -0.1885 & 0.6456 & -0.2349 & 0.3331 & -0.3113 \\
\hline & M-3 & 0.01521 & -0.2558 & 0.6853 & -0.1506 & 0.3539 & -0.2046 \\
\hline \multirow{3}{*}{ B } & M-1 & 0.01647 & -0.0526 & 0.6623 & -0.3852 & 0.1761 & -0.3670 \\
\hline & M-2 & 0.01806 & -0.1063 & 0.6487 & -0.1056 & 0.3599 & -0.1710 \\
\hline & M-3 & 0.01882 & -0.1486 & 0.6894 & -0.0074 & 0.4652 & -0.0407 \\
\hline \multirow{3}{*}{$\mathrm{C}$} & M-1 & 0.01695 & -0.1249 & 0.6331 & -0.2319 & 0.2834 & -0.2530 \\
\hline & M-2 & 0.01867 & -0.1360 & 0.6423 & -0.0392 & 0.3281 & -0.1522 \\
\hline & M-3 & 0.01885 & -0.1820 & 0.6398 & -0.0134 & 0.4729 & 0.0228 \\
\hline \multirow{3}{*}{$\mathrm{D}$} & M-1 & 0.01856 & -0.3552 & 0.1840 & -0.4107 & -0.3528 & -0.2842 \\
\hline & M-2 & 0.01845 & -0.3138 & 0.1603 & -0.5218 & -0.3968 & -0.2183 \\
\hline & M-3 & 0.01879 & -0.4419 & 0.1761 & -0.4699 & -0.2441 & -0.3578 \\
\hline \multirow{3}{*}{$\mathrm{E}$} & M-1 & 0.01279 & -0.3189 & -0.6744 & 0.4152 & 0.5908 & 0.0867 \\
\hline & M-2 & 0.01356 & -0.1342 & -0.6604 & 0.2347 & 0.4100 & -0.0741 \\
\hline & M-3 & 0.01584 & -0.0917 & -0.7250 & -0.2267 & 0.3244 & 0.2842 \\
\hline \multirow{3}{*}{$\mathrm{F}$} & M-1 & 0.01184 & -0.4926 & -0.6450 & 0.7515 & 0.6681 & -0.0578 \\
\hline & M-2 & 0.0135 & -0.1601 & -0.6929 & 0.2875 & 0.3995 & -0.0654 \\
\hline & M-3 & 0.0164 & -0.1059 & -0.6947 & -0.3240 & 0.2324 & 0.3735 \\
\hline \multirow{3}{*}{ G } & M-1 & 0.02293 & -0.2740 & -0.2792 & -0.5067 & -0.1422 & 0.3949 \\
\hline & M-2 & 0.0225 & -0.3045 & -0.3616 & -0.4459 & -0.0051 & 0.4148 \\
\hline & M-3 & 0.027 & -0.2587 & -0.0435 & -0.7873 & -0.3382 & 0.0911 \\
\hline \multirow{3}{*}{$\mathrm{H}$} & M-1 & 0.016 & -0.1139 & -0.3061 & 0.6364 & -0.3300 & -0.2287 \\
\hline & M-2 & 0.02061 & -0.1567 & -0.2239 & 0.5808 & -0.2669 & -0.2668 \\
\hline & M-3 & 0.01934 & -0.1113 & -0.1679 & 0.7529 & -0.3162 & -0.1062 \\
\hline \multirow{2}{*}{ I } & M-1 & 0.01662 & -0.08492 & -0.3681 & 0.6001 & -0.2468 & -0.2835 \\
\hline & M-2 & 0.0206 & -0.0922 & -0.2818 & 0.6385 & -0.2413 & -0.2610 \\
\hline \multirow{2}{*}{$\mathrm{J}$} & M-1 & 0.02013 & -0.3067 & -0.0618 & 0.4613 & -0.3885 & -0.1512 \\
\hline & M-2 & 0.02025 & -0.3378 & -0.0046 & 0.4840 & -0.3420 & -0.1010 \\
\hline \multirow{2}{*}{ K } & M-1 & 0.01834 & -0.2416 & 0.4702 & 0.2793 & 0.2366 & 0.3186 \\
\hline & M-2 & 0.01707 & -0.2933 & 0.3742 & 0.2261 & 0.1395 & 0.3423 \\
\hline \multirow{2}{*}{$\mathrm{L}$} & M-1 & 0.01734 & -0.1409 & 0.6193 & 0.2697 & 0.3152 & 0.2939 \\
\hline & M-2 & 0.01455 & -0.2956 & 0.4871 & 0.1795 & 0.2170 & 0.2732 \\
\hline
\end{tabular}

the output value as close as possible to the target value. In this ANN study, the neural network comprises of one input layer, one hidden layer with three neurons and one output layer. As we know, the Regression $(R)$ value indicates the quality of relationship among output and targets and varies from 0 to 1 . $R$-value of 0 and 1 stipulates chaotic and close relationship, respectively, among outputs and targets. The networks are initially trained with 500 epochs and incrementally increased with 100 more in each step unless the desired degree of accuracy is achieved. The flow chart for the training of ANN is already shown in Fig. 10. Finally, the networks are trained for deficient error, i.e., R-value is kept above 0.99 in each case. The percentage of the numerical simulation data utilized for the training and testing purposes of networks are $70 \%$ and $30 \%$ respectively.

The prepared networks can foresee the pressure coefficients and are plotted individually along with results of CFD and FFT for common faces like Face A, Face D, Face E and Face G in Figs. 13(a)-(d) respectively. The $95 \%$ prediction bounds of the FFT are also plotted in the same figures. Prediction bounds are often termed as confidence bounds as it exemplifies the confidence interval for a predicted response. In other words, the prediction bounds indicate that there is a $95 \%$ chance that a new observation is enclosed within the lower and upper bounds. As the response $C_{p e}$ is having a single predetermined 


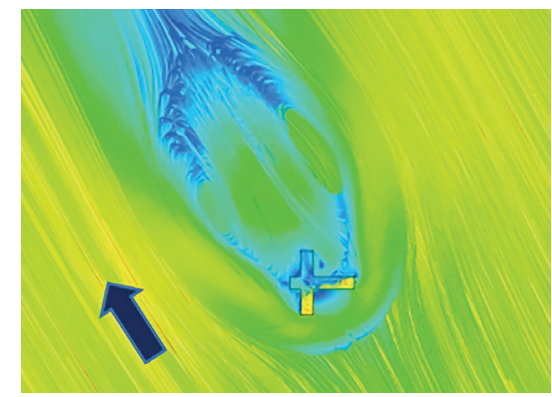

M-1

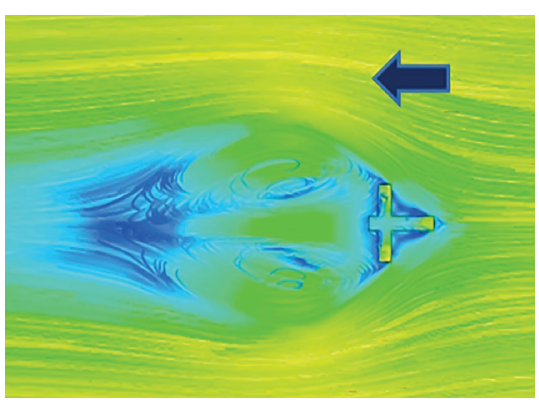

M-1

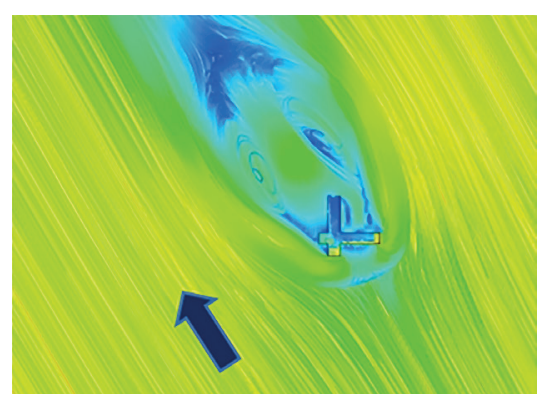

$\mathrm{M}-2$

(a) $120^{\circ}$ Wind Angle

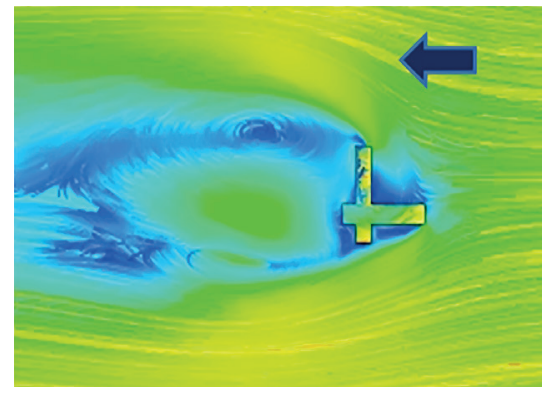

$\mathrm{M}-2$

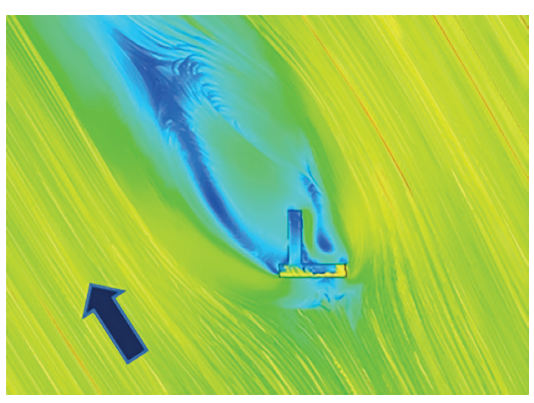

M-3

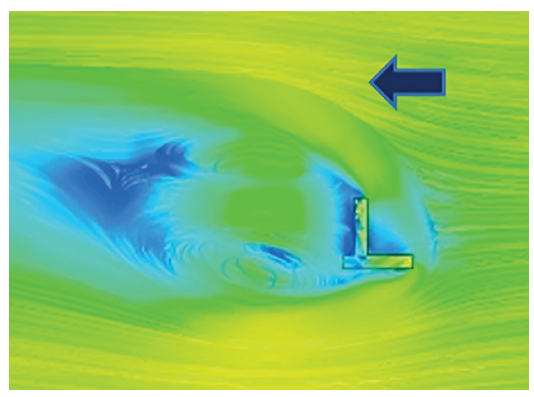

M-3

(b) $180^{\circ}$ Wind Angle

Fig. 11 Wind streamlines around the building models

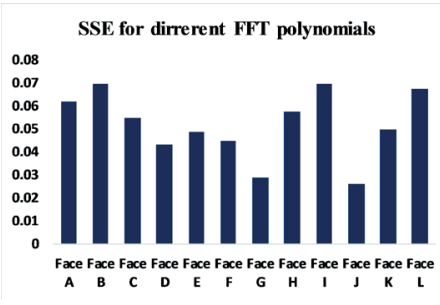

M-1

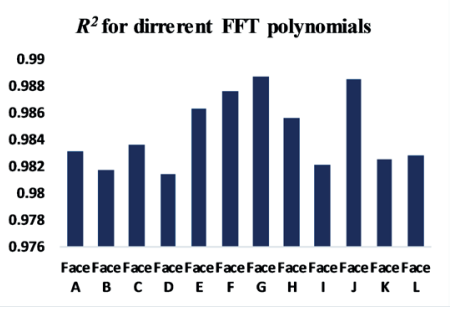

M-1

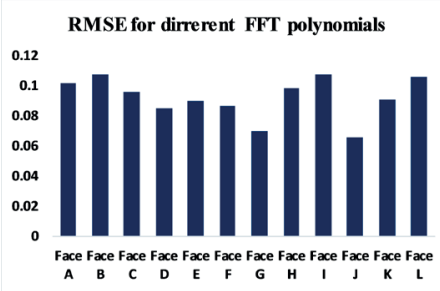

M-1

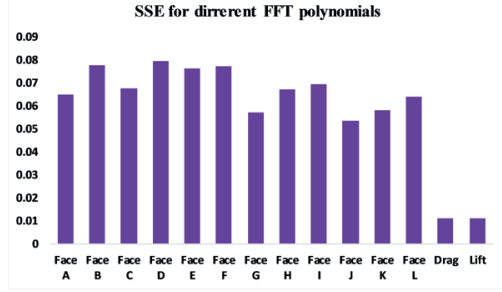

M-2

(a) $\mathrm{SSE}$

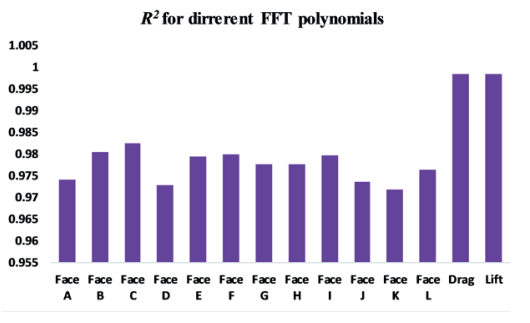

M-2

(b) $R^{2}$

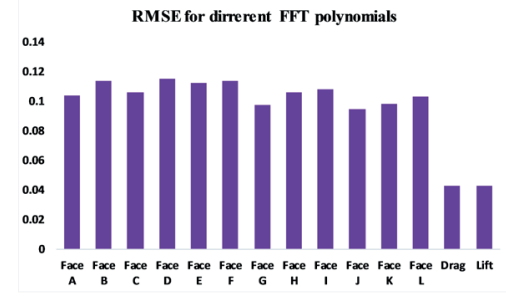

$\mathrm{M}-2$

(c) RMSE

Fig. 12 Error measurements of the FFT polynomials
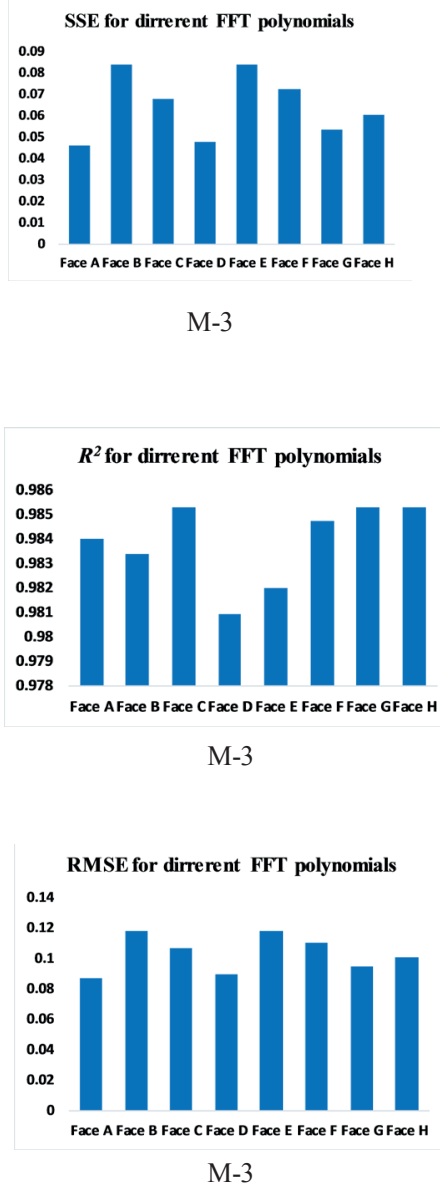
predictor value, non-simultaneous prediction bounds with a $95 \%$ confidence level have been considered. The nonsimultaneous prediction bounds for a new observation at the predictor value $x$ are given by,

$P_{U, L}=y \pm t \sqrt{s^{2}+x S x^{T}}$,

where $s^{2}$ is the mean squared error, $t$ is computed as the inverse of Student's $T$ cumulative distribution function, $S$ is the covariance matrix of the coefficient estimates, $\left(X^{T} X\right)^{-1} S^{2}$ and $x$ is a row vector of the Jacobian estimated at a particular predictor value.

From these comparative plots, it is evident that the results obtained from ANN are matching with good agreement with the results of both CFD and FFT. Therefore, ANN can be adequately trained to predict wind pressure coefficients. Later comparative plots for ANN predictions are face-wise plotted for all the building models to understand the shape effect.

The error histograms for Face B, Face C, Face E and Face F are shown in Figs. 14(a)-(d) to justify the accuracy of the trained networks. It is observed from the error histograms that the percentage of error is usually not more than $2 \%$. There are very few instances when the error is $3-5 \%$ but never more than $5 \%$. The error percentage is justified considering the randomness of responses during wind-structure interaction under wind storm and a number of variables involved in the responses.

Relevant standards for evaluation of wind loads do not include the pressure coefficients for cross-shaped buildings. Therefore, no guidelines are available, and specialized literature is the only source of information as far as the evaluation of wind loads with sufficient precision is a concern. So, in this article, an attempt is made to provide the general trend of variation of pressure coefficients on different building surfaces of tall cross-shaped buildings. For a more comprehensive study, in addition to the three parametric models already introduced, six other models (M-4 to M-9) are considered (Fig. 15). The height of all the building models is considered as $500 \mathrm{~mm}$.

Artificial Neural Networks are trained for all nine parametric models using the methodology already discussed in the preceding sections. The trained networks are plotted for different faces corresponding to different $d_{/} b$ and $h / b$ values (Refer Fig. 1) to show the trend of pressure coefficients due to change in shape for cross-plan shaped buildings keeping the same plan area. By altering the position and the length of the horizontal limbs on opposite sides, nine parametric models are generated as shown in Table 1 and Fig. 15. ANN predictions of mean pressure coefficients are presented. Figs. 16(a-1), gives the ANN predictions of $C_{p e}$ for different $d_{/} b$ values corresponding to a constant value of $h / b=5$. Whereas, Figs. 17(a-1) and Figs. 18(a)-(h) represents the ANN predictions of $C_{p e}$ for different $d / b$ values corresponding to a constant value of $h / b=3.33$ and $h / b=2.5$, respectively. Any Intermediate values may be suitably interpolated.

\section{Conclusions}

This particular study is concentrated on wind-induced responses of cross-plan shaped tall buildings. The required design parameters for the structure, like mean wind pressures coefficients on different building faces are obtained for different wind incidence angle varying from $0^{\circ}$ to $330^{\circ}$ at an increment of $30^{\circ}$. The study is initially conducted with three parametric models using CFD, and then results are compared with Fourier expansion polynomials and Artificial Neural Network. After observing reasonably good agreement among results of CFD, FFT and ANN, Artificial Neural Networks are trained for another six models. The trends of $C_{p e}$ with the variation of location and length of the horizontal limbs on opposite sides are presented. Following conclusions can be drawn from this specific study:

1. Computational fluid dynamics can be used for generating reliable wind response data.

2. From the wind streamlines or flow patterns, it is observed that there is a vortex generation in the wake region. These wake region vortices cause significant deflection of structures.

3. FFT polynomials using Fourier expansion with only two numbers of terms can be efficiently fitted for predicting wind response. The error measurement using SSE, $R^{2}$ and RMSE indicates the applicability of the polynomials.

4. In this study, the predicted values from ANN models and the desired values of the $C_{p e}$ are nearly overlying each other, indicating that the developed ANN models are satisfactory to estimate the wind responses. Hence a significant conclusion of this study is the viability of ANN for acquiring wind-induced responses along with experimental and CFD studies.

5. This threefold study making predictions for determining the responses of cross-plan shaped tall buildings subjected to wind storm covering all possible wind incidence angles can be beneficial in the actual design against wind load. The outcomes of this study can considerably reduce the resources, labor and analysis time for the building designers. 


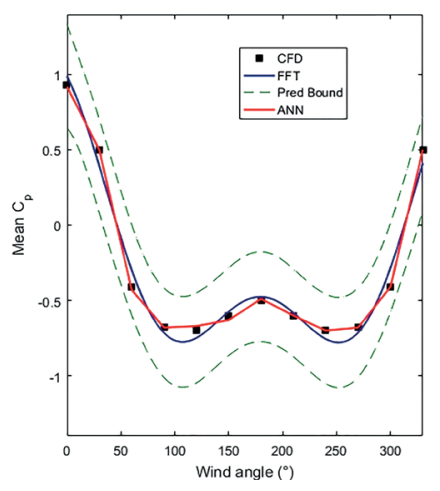

M-1

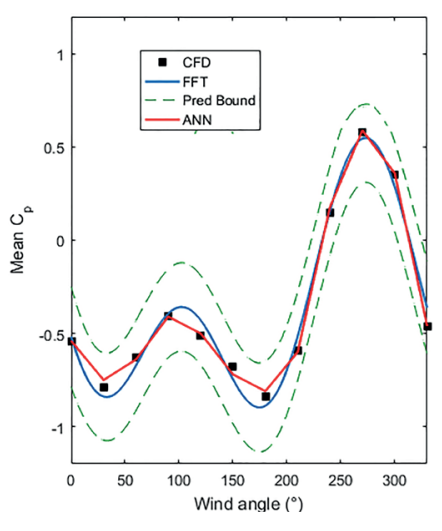

M-1

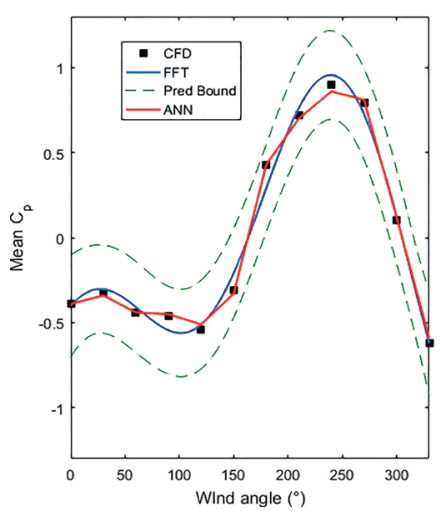

M-1

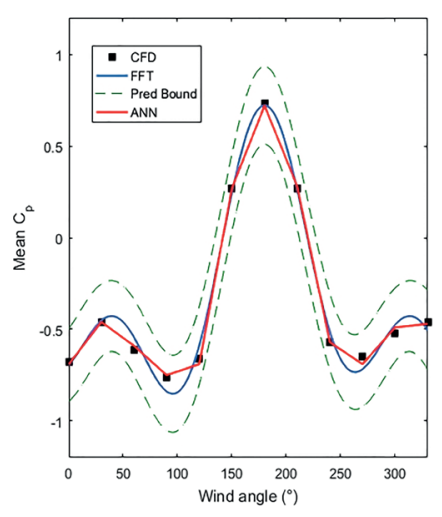

M-1

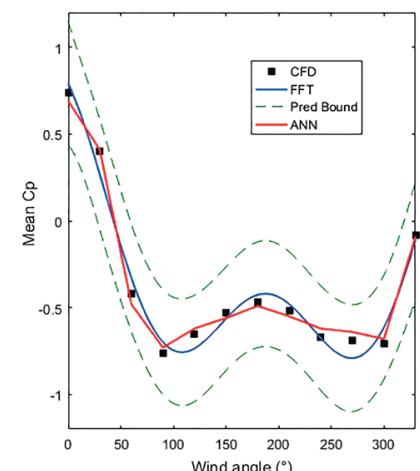

M-2

(a) Face $\mathrm{A}$

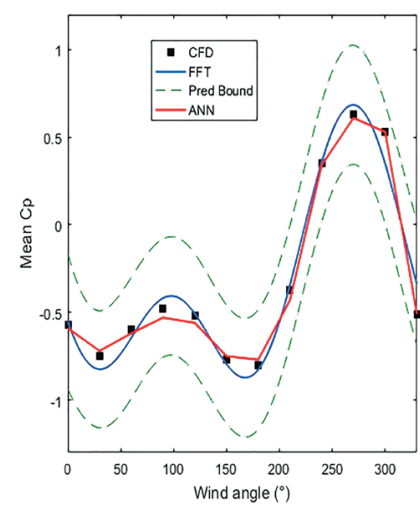

M-2

(b) Face D

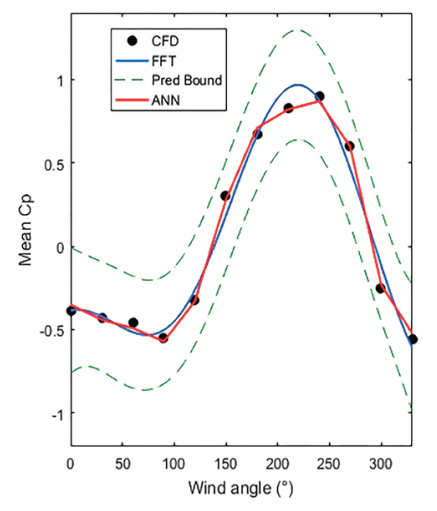

M-2

(c) Face E

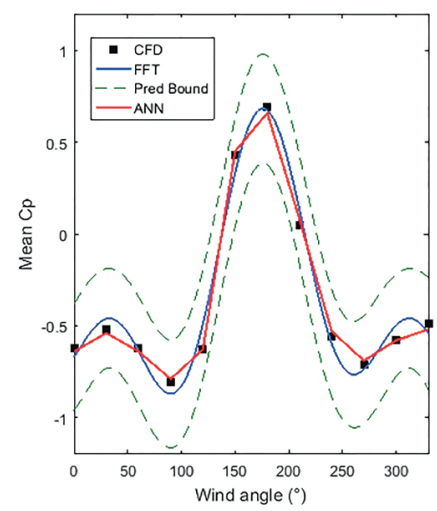

M-2

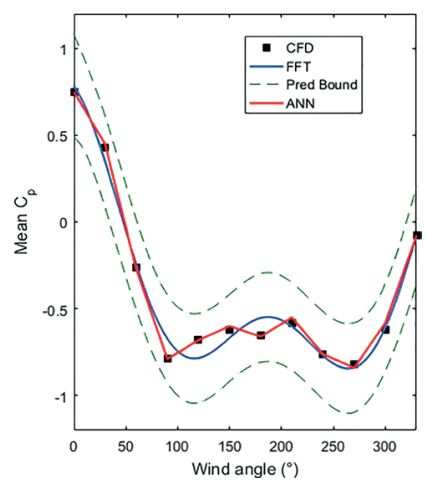

M-3

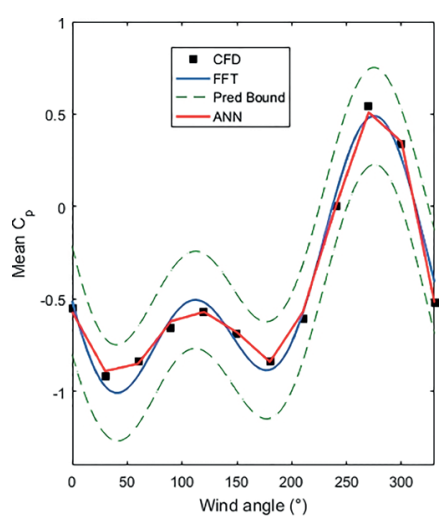

M-3

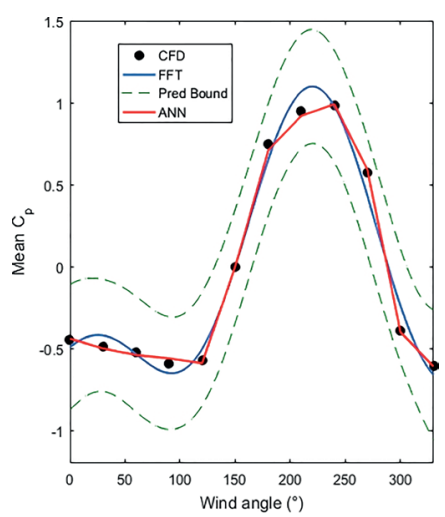

M-3

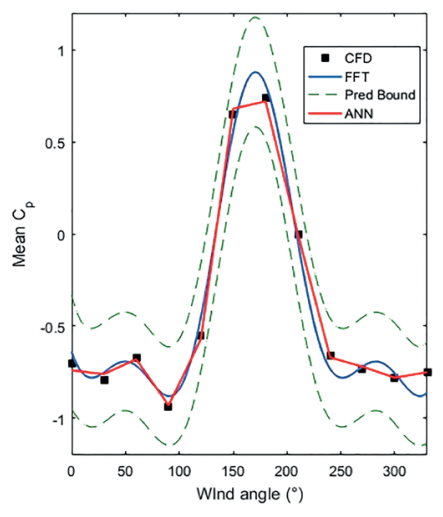

M-3

(d) Face G

Fig. 13 The plot of Pressure coefficients obtained using CFD, FFT and ANN 

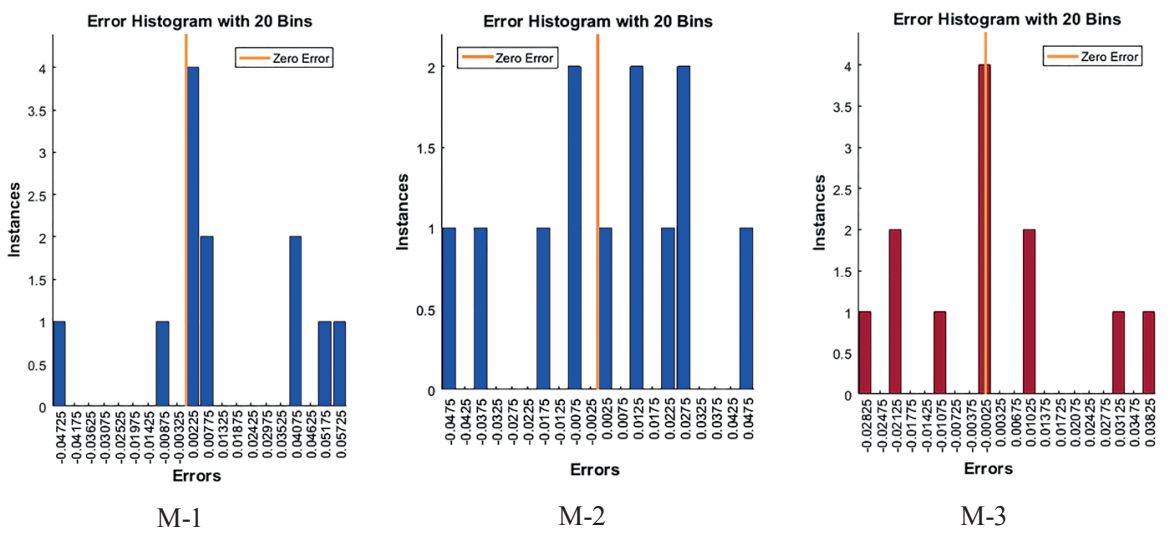

(a) Face $\mathrm{B}$

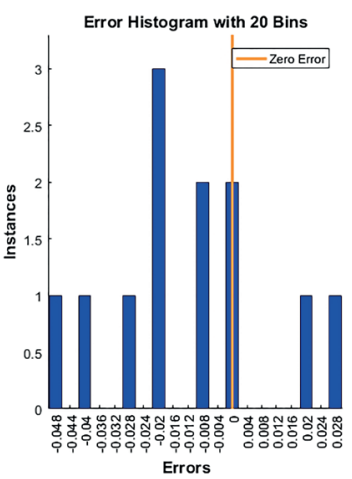

M-1

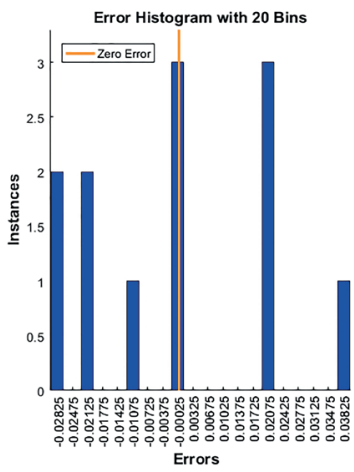

M-1

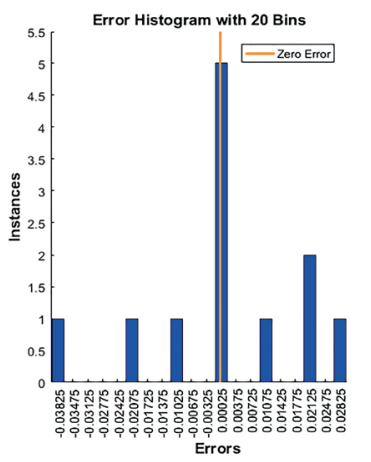

M-1

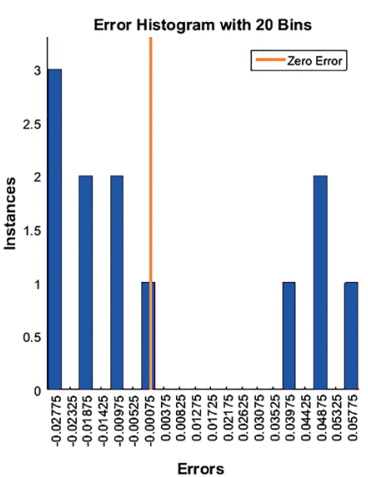

M-2

(b) Face $\mathrm{C}$

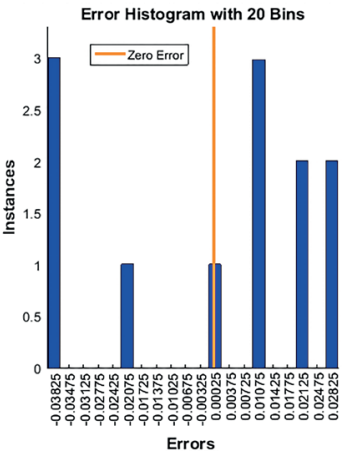

M-2

(b) Face $\mathrm{E}$

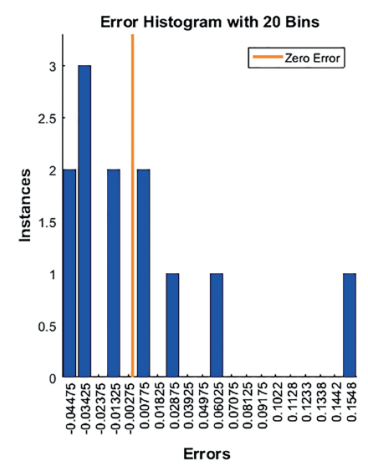

M-2

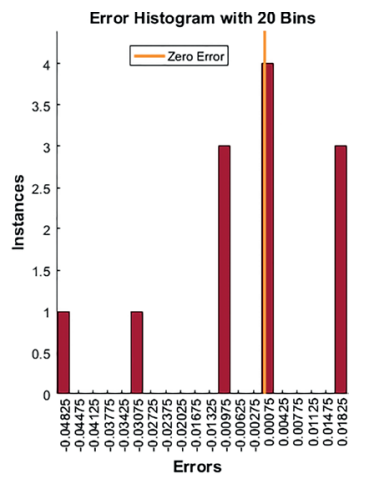

M-3
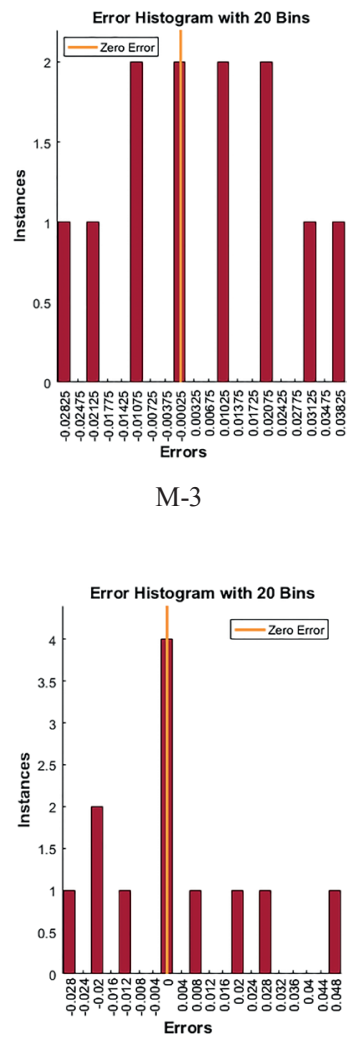

M-3

(d) Face F

Fig. 14 Error histograms of different ANN predictions of pressure coefficients 


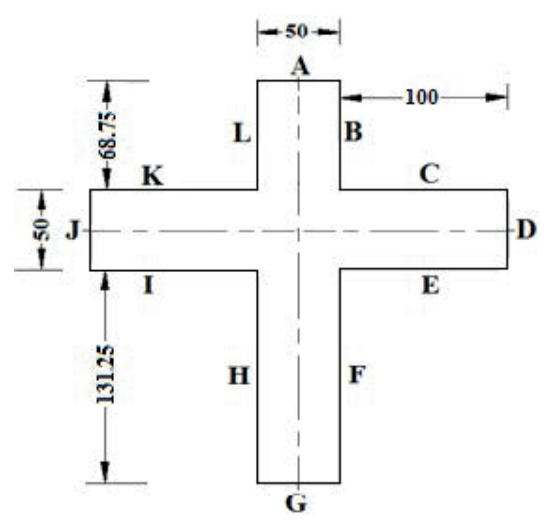

(a) $\mathrm{M}-4\left(\frac{d}{b}=1.31, \frac{h}{b}=5\right)$

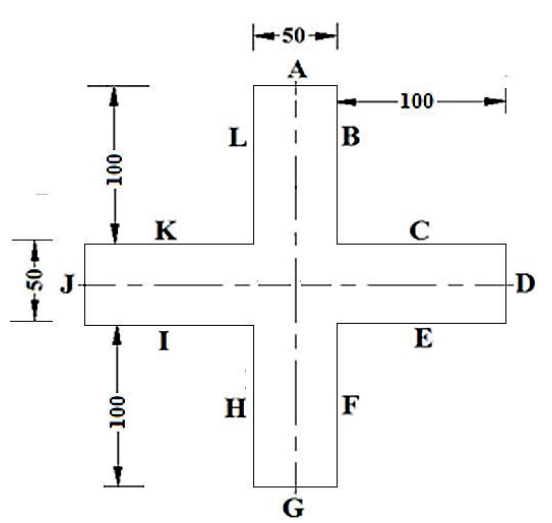

$$
\text { (d) } \mathrm{M}-7\left(\frac{d}{b}=1, \frac{h}{b}=5\right)
$$

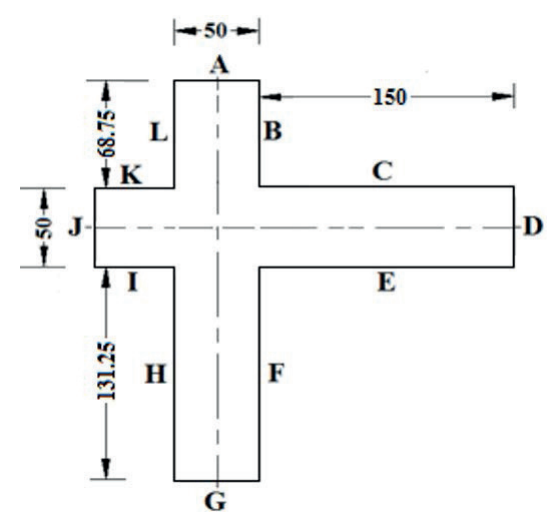

(b) $\mathrm{M}-5\left(\frac{d}{b}=0.88, \frac{h}{b}=3.33\right)$

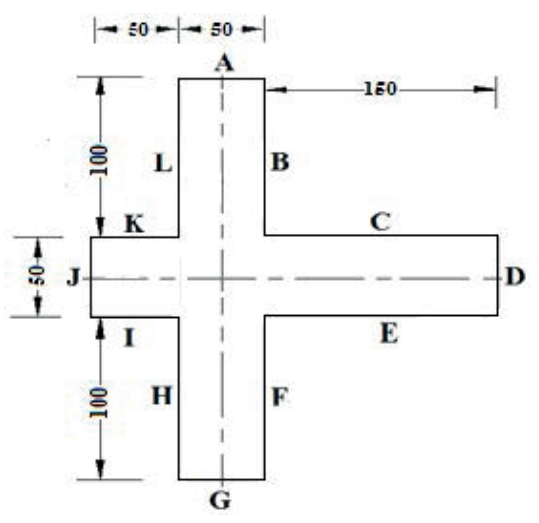

(e) $\mathrm{M}-8\left(\frac{d}{b}=0.66, \frac{h}{b}=3.33\right)$

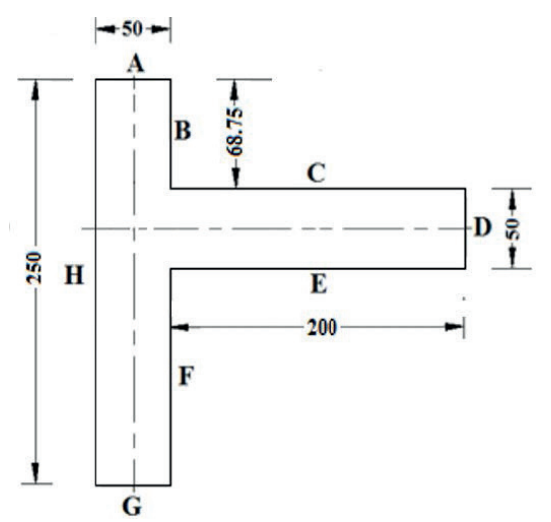

(c) M-6 $\left(\frac{d}{b}=0.66, \frac{h}{b}=2.5\right)$

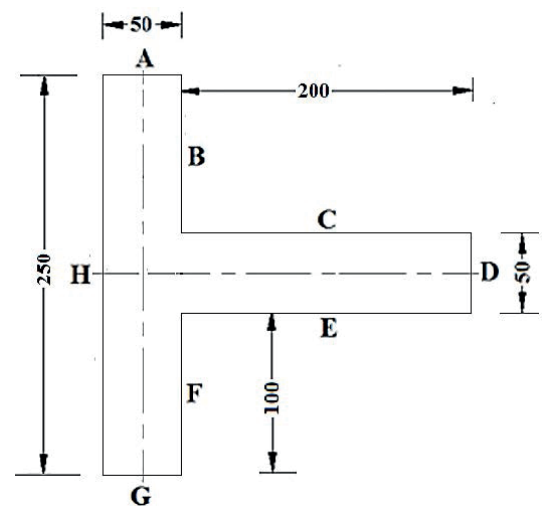

(f) $\mathrm{M}-9\left(\frac{d}{b}=0.5, \frac{h}{b}=2.5\right)$

Fig. 15 Definition of the building surfaces and dimensions of six additional models for the comprehensive study (All units are in $\mathrm{mm}$ ) 


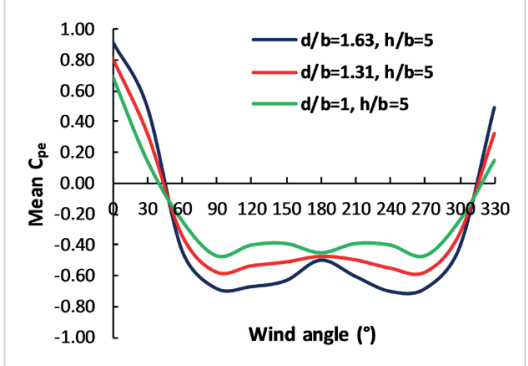

(a) Face A

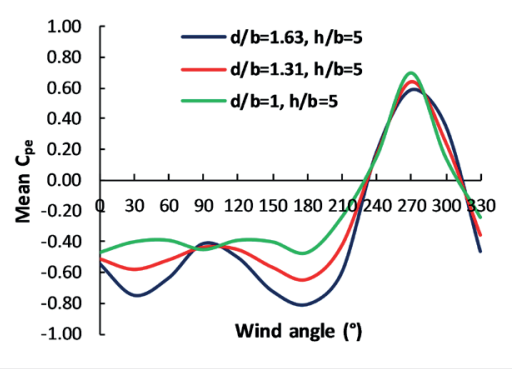

(d) Face D

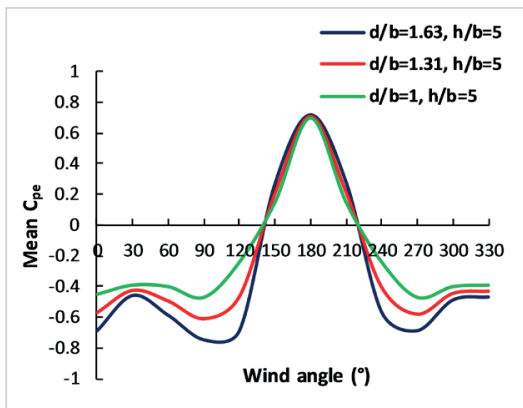

(g) Face G

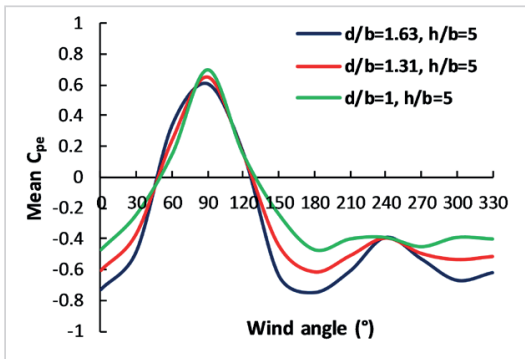

(j) Face J

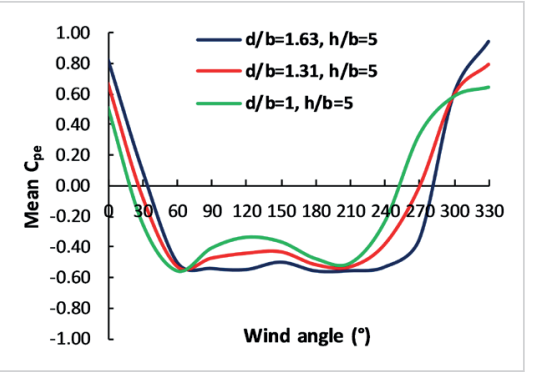

(b) Face B

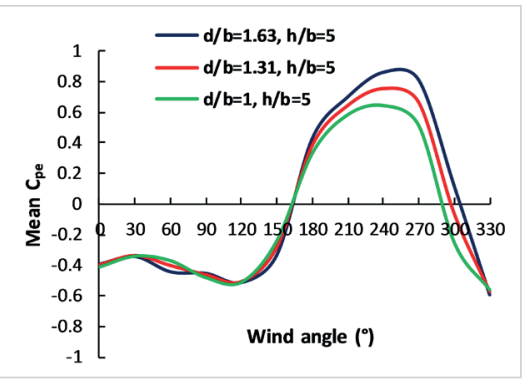

(e) Face $\mathrm{E}$

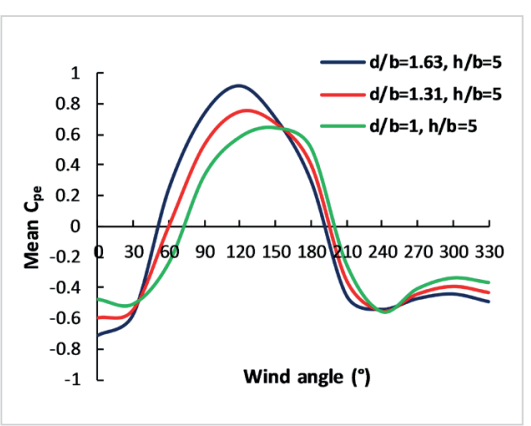

(h) Face $\mathrm{H}$

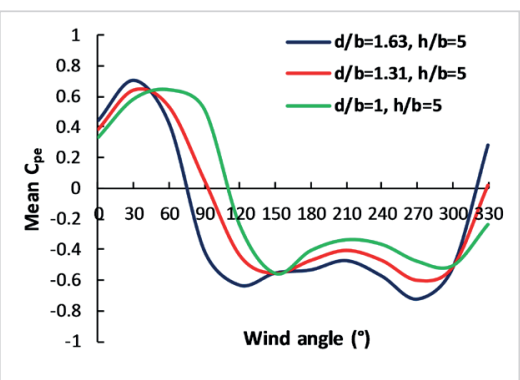

(k) Face K

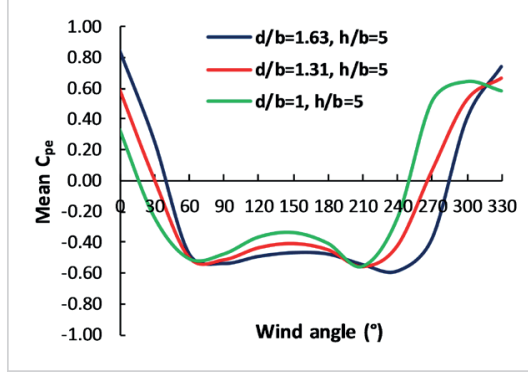

(c) Face $\mathrm{C}$

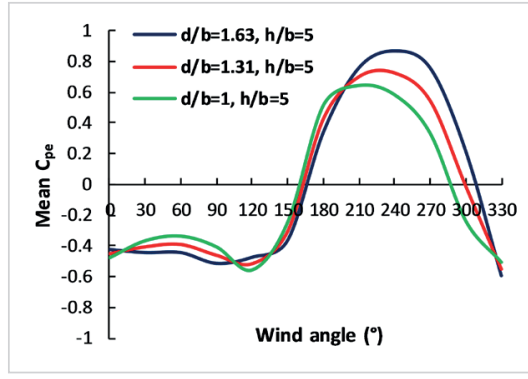

(f) Face F

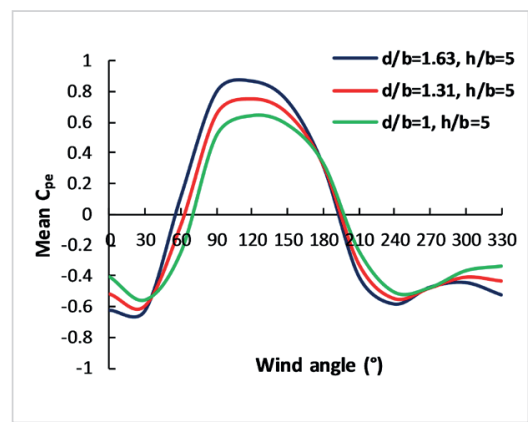

(i) Face I

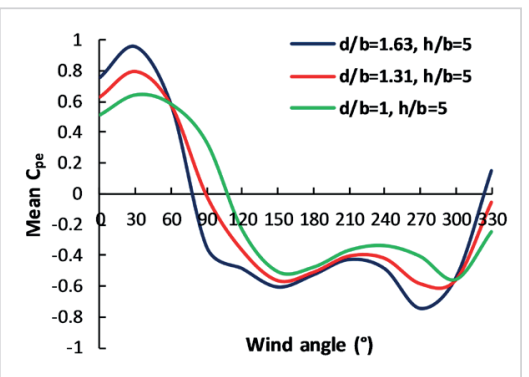

(1) Face L

Fig. 16 Trends of ANN predictions among the parametric models of $h / b=5$ 


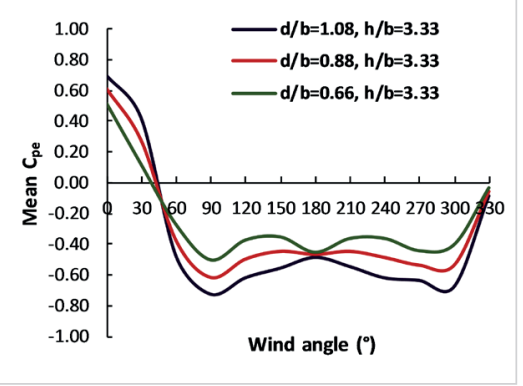

(a) Face $\mathrm{A}$

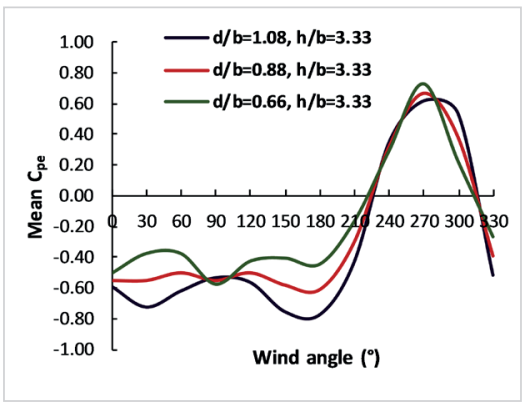

(d) Face D

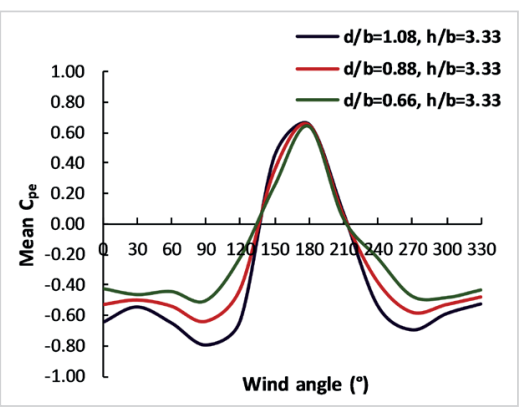

(g) Face G

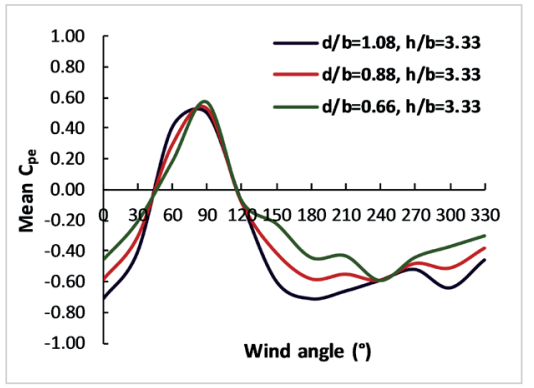

(j) Face J

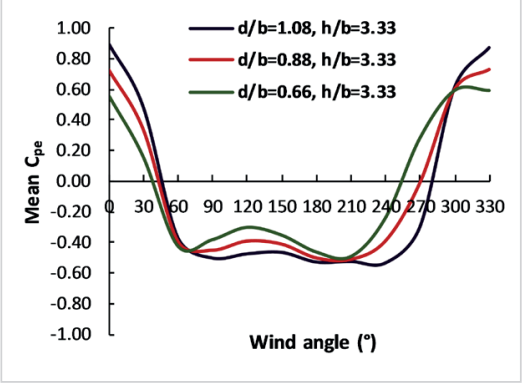

(b) Face B

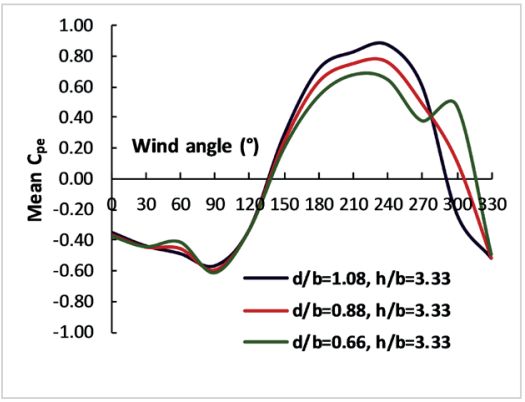

(e) Face E

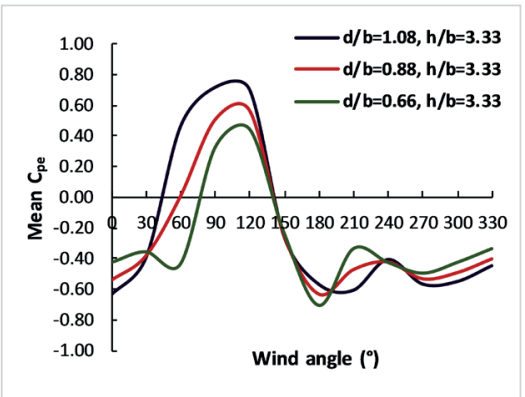

(h) Face $\mathrm{H}$

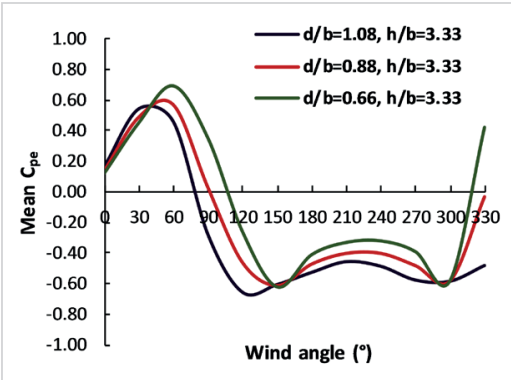

(k) Face $\mathrm{K}$

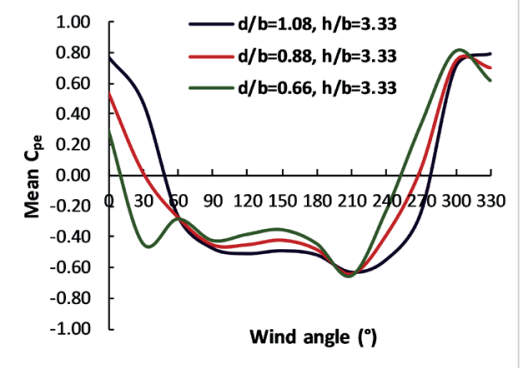

(c) Face $\mathrm{C}$

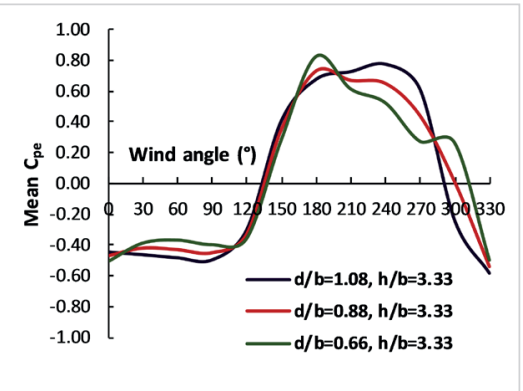

(f) Face $\mathrm{F}$

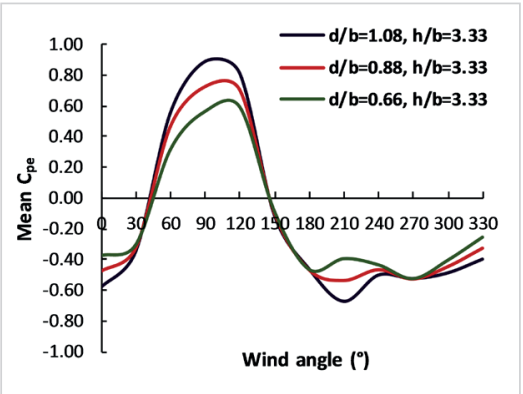

(i) Face I

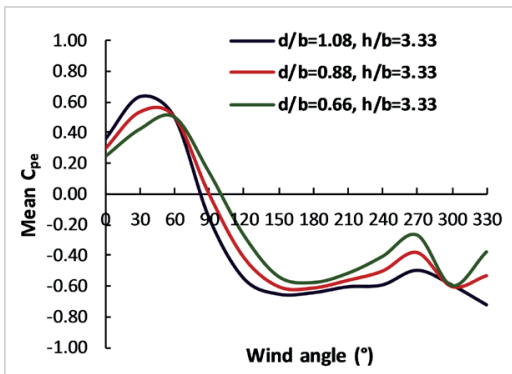

(1) Face L

Fig. 17 Trends of ANN predictions among the parametric models of $h / b=3.33$ 


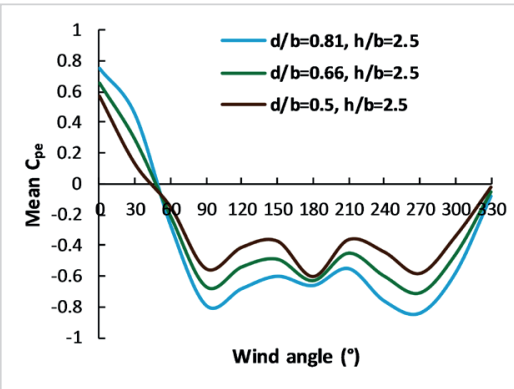

(a) Face $\mathrm{A}$

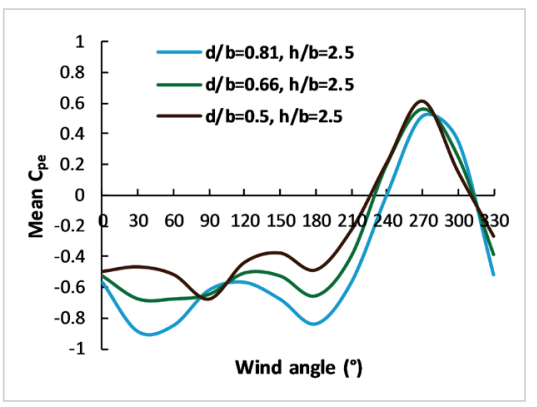

(d) Face D

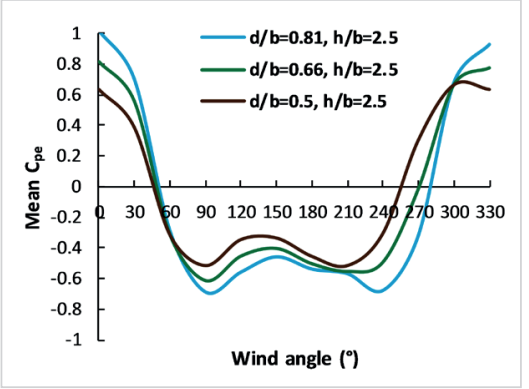

(b) Face B

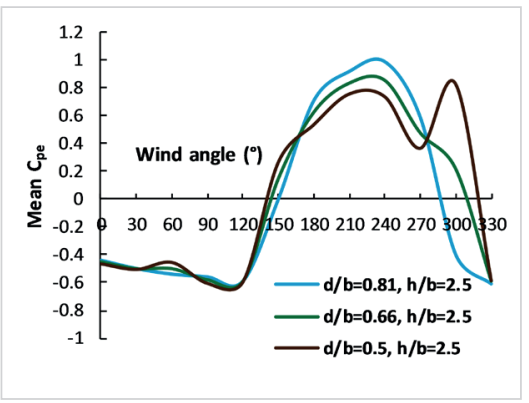

(e) Face E

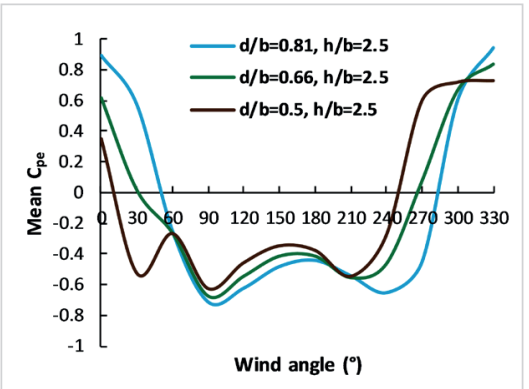

(c) Face $\mathrm{C}$

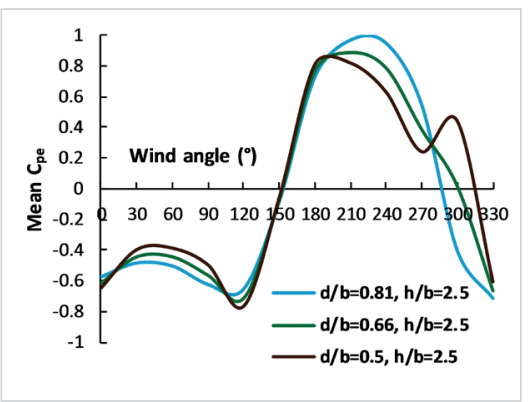

(f) Face F

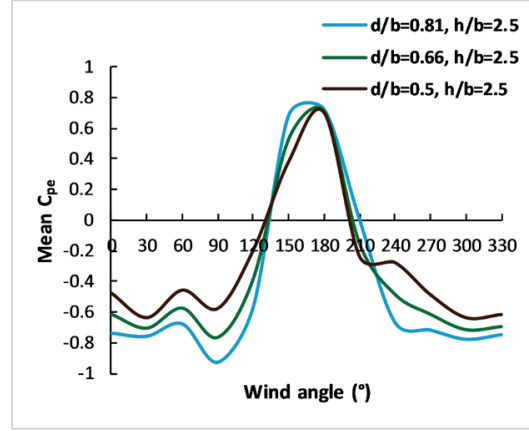

(g) Face G

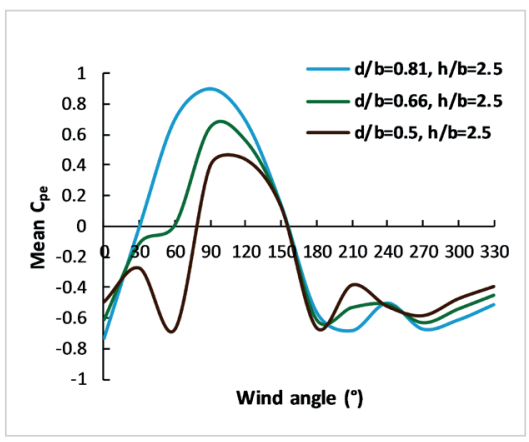

(h) Face $\mathrm{H}$

Fig. 18 Trends of ANN predictions among the parametric models of $h / b=2.5$

\section{References}

[1] Lin, N., Letchford, C., Tamura, Y., Liang, B., Nakamura, O. "Characteristics of wind forces acting on tall buildings", Journal of Wind Engineering and Industrial Aerodynamics, 93(3), pp. 217$242,2005$.

https://doi.org/10.1016/j.jweia.2004.12.001

[2] Gómes, M. G., Rodrigues, A. M., Mendes, P. "Experimental and numerical study of wind pressures on irregular-plan shapes", Journal of Wind Engineering and Industrial Aerodynamics, 93(10), pp. 741756, 2005.

https://doi.org/10.1016/j.jweia.2005.08.008

[3] Irwin, P. A. "Bluff body aerodynamics in wind engineering", Journal of Wind Engineering and Industrial Aerodynamics, 96(6-7), pp. 701-712, 2008.

https://doi.org/10.1016/j.jweia.2007.06.008
[4] Tse, K. T., Hitchcock, P. A., Kwok, K. C. S., Thepmongkorn, S., Chan, C. M. "Economic perspectives of aerodynamic treatments of square tall buildings", Journal of Wind Engineering and Industrial Aerodynamics, 97(9-10), pp. 455-467, 2009. https://doi.org/10.1016/j.jweia.2009.07.005

[5] Tanaka, H., Tamura, Y., Ohtake, K., Nakai, M., Kim, Y. C. "Experimental investigation of aerodynamic forces and wind pressures acting on tall buildings with various unconventional configurations", Journal of Wind Engineering and Industrial Aerodynamics, 107-108, pp. 179-191, 2012.

https://doi.org/10.1016/j.jweia.2012.04.014

[6] Muehleisen, R. T., Patrizi, S. "A new parametric equation for the wind pressure coefficient for low-rise buildings", Energy and Buildings, 57, pp. 245-249, 2013.

https://doi.org/10.1016/j.enbuild.2012.10.051 
[7] Verma, S. K., Ahuja, A. K., Pandey, A. D. "Effects of wind incidence angle on wind pressure distribution on square pan tall buildings", Journal of Academic Industrial Research, 1(12), pp. 747-752, 2013. [online] Available at: http://jairjp.com/MAY\%202013/04\%20 VERMA.pdf

[8] Chakraborty, S., Dalui, S. K., Ahuja, A. K. "Experimental Investigation of Surface Pressure on '+' Plan Shape Tall Building", Jordan Journal of Civil Engineering, 8(3), pp. 251-262, 2014. [online] Available at: https://jjce.just.edu.jo/issues/show_paper. php?pid=2750

[9] Bhattacharyya, B., Dalui, S. K. "Investigation of mean wind pressures on 'E' plan shaped tall building", Wind and Structures, 26(2), pp. $99-114,2018$.

https://doi.org/10.12989/was.2018.26.2.099

[10] Zhang, A., Gu, M. "Wind tunnel tests and numerical simulations of wind pressures on buildings in staggered arrangement", Journal of Wind Engineering and Industrial Aerodynamics, 96(10-11), pp. 2067-2079, 2008.

https://doi.org/10.1016/j.jweia.2008.02.013

[11] Tominaga, Y., Stathopoulos, T. "CFD Modelling of Pollution Dispersion in Building Array: Evaluation of turbulent scalar flux modelling in RANS model using LES results", Journal of Wind Engineering and Industrial Aerodynamics, 104-106, pp. 484-491, 2012. https://doi.org/10.1016/j.jweia.2012.02.004

[12] Paul, R., Dalui, S. K. "Wind effects on 'Z' plan-shaped tall building: a case study", International Journal of Advanced Structural Engineering, 8, pp. 319-335, 2016. https://doi.org/10.1007/s40091-016-0134-9

[13] Kumar, D., Dalui, S. K. "Effect of internal angles between limbs of cross plan shaped tall building under wind load", Wind and Structures, 24(2), pp. 95-118, 2017. https://doi.org/10.12989/was.2017.24.2.095

[14] Li, Y., Tian, X., Tee, K. F., Li, Q.-S., Li, Y.-G. "Aerodynamic treatments for reduction of wind loads on high-rise Building", Journal of Wind Engineering and Industrial Aerodynamics, 172, pp. 107$115,2018$. https://doi.org/10.1016/j.jweia.2017.11.006

[15] Sanyal, P., Dalui, S. K. "Effect of courtyard and opening on a rectangular plan shaped tall building under wind load", International Journal of Advanced Structural Engineering, 10, pp. 169-188, 2018. https://doi.org/10.1007/s40091-018-0190-4

[16] Nikose, T. J., Sonparote, R. S. "Dynamic wind response of tall buildings using artificial neural network", The Structural Design of Tall and Special Buildings, 28(13), Article ID: e1657, 2019. https://doi.org/10.1002/tal.1657

[17] Kaveh, A., Iranmanesh, A. "Comparative Study of Backpropagation and Improved Counterpropagation Neural Nets in Structural Analysis and Optimization", International Journal of Space Structures, 13(4), pp. $177-185,1998$. https://doi.org/10.1177/026635119801300401

[18] Iranmanesh, A., Kaveh, A. "Structural optimization by gradient-based neural networks", International Journal for Numerical Methods in Engineering, 46(2), pp. 297-311, 1999. https://doi.org/10.1002/(SICI)1097-0207(19990920)46:2<297:: AID-NME679>3.0.CO;2-C
[19] Kaveh, A., Servati, H. "Design of double layer grids using backpropagation neural networks", Computers and Structures, 79(17), pp. 1561-1568, 2001. https://doi.org/10.1016/S0045-7949(01)00034-7

[20] Kaveh, A., Elmieh, R., Servati, H. "Prediction of moment-rotation characteristic for semi-rigid connections using BP neural networks", Asian Journal of Civil Engineering, 2(2), pp. 131-142, 2001.

[21] Kaveh, A., Fazel-Dehkordi, D., Servati, H., "Prediction of MomentRotation Characteristic for Saddle-like Connections using FEM and BP Neural Networks", In: Topping, B. H. V. (ed.) Computational Engineering using Metaphors from Nature, Civil-Comp Press, Edinburgh, UK, 200, pp. 15-24.

https://doi.org/10.4203/ccp.64.1.3

[22] Fu, J. Y., Li, Q. S., Xie, Z. N. "Prediction of wind loads on a large flat roof using fuzzy neural networks", Engineering Structures, 28(1), pp. 153-161, 2006. https://doi.org/10.1016/j.engstruct.2005.08.006

[23] Kaveh, A., Gholipour, Y., Rahami, H. "Optimal Design of Transmission Towers Using Genetic Algorithm and Neural Networks", International Journal of Space Structures, 23(1), pp. 1-19, 2008. https://doi.org/10.1260/026635108785342073

[24] Mengistu, T., Ghaly, W. "Aerodynamic optimization of turbomachinery blades using evolutionary methods and ANN-based surrogate models", Optimization and Engineering, 9, pp. 239-255, 2008. https://doi.org/10.1007/s11081-007-9031-1

[25] Wang, J., Cheng, C.-M. "The Application of Artificial Neural Networks to Predict Wind Spectra for Rectangular Cross-Section Buildings", presented at The Fifth International Symposium on Computational Wind Engineering (CWE2010), Chapel Hill, NC, USA, May, 23-27, 2010.

[26] Rofooei, F. R., Kaveh, A., Farahani, F. M. "Estimating the vulnerability of the concrete moment resisting frame structures using artificial neural networks", International Journal of Optimization in Civil Engineering, 1(3), pp. 433-448, 2011.

[27] Vyavahare, A. Y., Godbole, P. N., Nikose, T. "Analysis of tall building for across wind response", International Journal of Civil and Structural Engineering, 2(3), pp. 979-986, 2012. https://doi.org/10.6088/ijcser.00202030024

[28] Verma, S. K., Kumar, K., Kaur, H. "Estimation of Coefficient of Pressure in High Rise Buildings Using Artificial Neural Network", International Journal of Engineering Research and Applications, 4(4), pp. 105-110, 2014. [online] Available at: https://www.researchgate.net/publication/311922080_Estimation_of_Coefficient_of_ Pressure_in_High_Rise_Buildings_Using_Artificial_Neural_ Network

[29] BIS "IS 875 (Part-3) Code of practice for the design loads (Other than Earthquake) for buildings and structures (Part-3, Wind Loads)", Bureau of Indian Standards, New Delhi, India, 2015.

[30] Nikose, T. J., Sonparote, R. S. "Dynamic along wind response of tall buildings using Artificial Neural Network", Cluster Computing, 22, pp. 3231-3246, 2019. https://doi.org/10.1007/s10586-018-2027-0

[31] San, O., Maulik, R. "Extreme learning machine for reduced order modeling of turbulent geophysical flows", Physical Review E, 97, Article number: 042322, 2018. https://doi.org/10.1103/PhysRevE.97.042322 
[32] Lui, H. F. S., Wolf, W. R. "Construction of reduced-order models for fluid flows using deep feedforward neural networks", Journal of Fluid Mechanics, 872, pp. 963-994, 2019.

https://doi.org/10.1017/jfm.2019.358

[33] Mallick, M., Mohanta, A., Kumar, A., Patra, K. C. "Prediction of Wind-Induced Mean Pressure Coefficients Using GMDH Neural Network", Journal of Aerospace Engineering, 33(1), pp. 1-17, 2019.

https://doi.org/10.1061/(ASCE)AS.1943-5525.0001101

[34] Revuz, J., Hargreaves, D. M., Owen, J. S. "On the domain size for the steady-state CFD modelling of a tall building", Wind and Structures, 15(4), pp. 313-329, 2012. https://doi.org/10.12989/was.2012.15.4.313

[35] Dalui, S. K. "Wind Effects on Tall Buildings with Peculiar Shape", PhD Thesis, Indian Institute of Technology, 2008. [online] Available at: http://hdl.handle.net/123456789/1633
[36] Hunter, D., Yu, H., Pukish, M. S., Kolbusz, J., Wilamowski, B. M. "Selection of Proper Neural Network Sizes and Architectures-A Comparative Study", IEEE Transactions on Industrial Informatics, 8(2), pp. 228-240, 2012. https://doi.org/10.1109/TII.2012.2187914

[37] Levenberg, K. "A Method for the Solution of Certain Non-Linear Problems in Least Squares", Quarterly of Applied Mathematics, 2(2), pp. 164-168, 1944. https://doi.org/10.1090/qam/10666

[38] Marquardt, D. W. "An Algorithm for Least-Squares Estimation of Nonlinear Parameters", Journal of the Society for Industrial and Applied Mathematics, 11(2), pp. 431-441, 1963. https://doi.org/10.1137/0111030

[39] Hagan, M. T., Menhaj, M. B. "Training feedforward networks with the Marquardt algorithm", IEEE Transactions on Neural Networks, 5(6), pp. 989-993, 1994.

https://doi.org/10.1109/72.329697 